\title{
Trust and Cooperation at a Confluence of Worlds: An Experiment in Xinjiang, China
}

\author{
Zhe Zhang, Louis Putterman, and Xu Zhang*
}

\begin{abstract}
We study trust and willingness to cooperate among and between Uyghur and Han college students in Xinjiang, China, where tensions exist between the two ethnic groups. We conduct an incentivized laboratory-style decision-making experiment in which within and between group interactions occur among identifiable participants without traceability of individual decisions. We find that members of each ethnicity show favoritism towards those of their own ethnicity in both trust and cooperation and that communication enhances interethnic cooperation significantly. We also find that Uyghur and Han subjects behave differently in their willingness to cooperate relative to trust, although both trust and trustworthiness positively correlate with willingness to cooperate on the individual level.
\end{abstract}

Keywords: trust, cooperation, experiment, culture, ethnicity, discrimination JEL codes: C91, O15, D64, H41

\section{Introduction}

Understanding trust and cooperation among conflicted ethnic groups is crucial for overcoming the economic underdevelopment in regions where such groups coexist (Easterly and Levine, 1997; Alesina et al., 1999; Montalvo and Reynal-Querol, 2005). However, few

\footnotetext{
* Ph.D. candidate in Political Science, Professor of Economics, and Ph.D. candidate in Economics, respectively, Brown University, Providence, RI 02912, USA. The protocol of the experiment reported here was assigned exempt status by the Brown University Institutional Review Board. We thank the China Initiative of the Watson Institute for International and Public Affairs, Brown University, for funding of the research conducted in Xinjiang by co-author Zhe Zhang.
} 
studies on trust and ethnicity have been conducted in regions under ongoing ethnic conflicts, and there are fewer studies still on inter-ethnic cooperation, potentially due to the complexity of data collection there. Since ethnicity-related topics are so sensitive, local authorities may not permit open scholarly inquiry and subjects may not report truthfully, either.

In this paper, we study the effects of observing the ethnic composition of a group on within-group trust and cooperation in a region under ethnic conflict, and address the data collection difficulty with a novel experimental design that draws less or no attention to our research interest in inter-ethnic relations. Specifically, we modify the canonical trust game ${ }^{1}$ and public goods game ${ }^{2}$, which are widely used to study trust and cooperation respectively in experimental economics, to a face-to-face inter-ethnic context while avoiding explicit cues about ethnicity in the experiment. Our design allows the experimenter to keep track of the ethnicities of those who play an experimental game with knowledge of each other's ethnicity but without knowing that the experimenter is manipulating and studying the ethnic pairings. This feature makes our design appealing for studying such a sensitive topic like ethnic conflict in regions with ongoing tensions between ethnic groups.

We apply this design to an incentivised lab experiment in Xinjiang, China, where two main ethnic groups, Uyghur and Han, have frequent conflict. Xinjiang is an ideal setting for our study because Uyghur and Han look distinctly different, which facilitates our "face-toface, identifiable ethnicity, without explicit cue" set-up. In addition, the cultural differences

\footnotetext{
${ }^{1}$ The "trust game" (or "investment game") was first introduced by Berg et al. (1995), and has become the most commonly adopted paradigm of the experimental studies on trust. With this game in mind, Fehr (2009) defines trust as the act of voluntarily placing resources at another party's disposal in expectation of benefit but without legal or other means of guaranteeing it. See Johnson and Mislin (2011) and Eckel and Wilson (2011) for two recent surveys of studies based on the trust game.

2 The "public goods game" (or "voluntary contribution mechanism") is the most widely used "work horse" for the study of cooperation in social dilemmas (Zelmer, 2003), i.e. situations in which socially optimal outcomes are theoretically ruled out if each actor maximizes own payoff. We add the public goods game to the trust game in our research, because the former differs from the latter in entailing simultaneous rather than sequential decisions, and because cooperation in groups having more than two members (the groups we study contain four) may have different characteristics than dyadic cooperation, inter alia for reasons (perhaps) of culture related to ethnicity.
} 
between Uyghur and Han may lead to different patterns in their tendency to trust and willingness to cooperate. Inter-ethnic trust and cooperation in regions with these features have rarely been studied before, experimentally. To our knowledge, there is only one previous study of trust as measured by an experimental game that has been done with participants in a region having an ongoing ethnic conflict, the Israeli-Palestinian one by Henning-Schmidt et al. (2007). However, unlike in our setting, their subjects of those two ethnic groups were not in the same location when they participated, and explicit reference to the other group was made.

To compare trust and cooperation under different ethnic compositions, we conduct a two-part experiment: each subject plays three (one-shot) trust games (TG) in the first part and four (one-shot) public goods games (PGG) in the second. In the TG, we vary the ethnicity and identifiability of subjects' counterparts — which we define as "condition" — in each interaction. There are three conditions: pairing with a coethnic member, with a member of the other ethnicity, or with a member of unidentified ethnicity. Each subject goes through all three conditions.

Conditions in the PGG are defined not only by the ethnicity and identifiability of the group members, but also whether communication is allowed. The first three conditions are without communication and correspond to those in the TG: being in an ethnically homogenous group, in an ethnically mixed group (with equal split of two ethnicities), and in a group with anonymous others. The fourth condition in the PGG differs from the others in allowing face-to-face communication between subjects before individual decisions are made privately in an ethnically (equally) mixed group. This allows us to study the effect of communication on inter-ethnic cooperation.

In contrast to most related studies in which participants are informed in the instructions of the ethnic or national identity of their counterparts, we are able to observe 
interactions by both homogeneous and heterogeneous pairs and groups while avoiding such explicit cues. Having equal numbers of Uyghur and Han subjects in each experiment session need not have been a salient cue, since the two ethnicities jointly predominate and have similar numbers in the school and in the region where our experiment was conducted. During the experiment, we never refer to trust, cooperation or ethnicity explicitly, but have students seated in a way that they can recognize each identifiable partner's ethnic identity by their obviously different appearance. We also make it appear as if subjects were paired or grouped without the concern of ethnicity. For example, in each round of TG where subjects play with identifiable others, there are always an equal number of coethnic pairs and non-coethnic pairs, thus appearing to be random. We assure that all participants play once with a coethnic and once with a subject of the other ethnicity, yet in no interaction giving the impression that the experimenter has intentionally arranged for all to play with a member of their own or of the other ethnicity.

We have 3 major findings from the experimental results. First, members of each ethnicity (i.e., Uyghur or Han) show favoritism towards those of their own ethnicity in both trust and cooperation. Second, communication enhances inter-ethnic cooperation significantly. Third, Uyghur and Han subjects behave differently in their tendency to cooperate relative to their inclination to trust.

Each of these findings contributes to a line of existing literature. First, our results add to the evidence of within-group favouritism. Although the majority of studies on trust and ethnicity have found that individuals behave in ways that are more favorable towards coethnics than out-group members (Habyarimana et al., 2007; Miguel and Gugerty, 2005; Khwaja, 2001; Alesina et al., 1999; Chen et al., 2017), none of them were conducted in a region under conflict between two distinct ethnic groups like Xinjiang, and the only study similar to ours, the Palestinian-Israeli study by Hennig-Schmidt et al. (2007), found the 
surprising result that Palestinian students were highly trusting and trustworthy towards Jewish Israeli ones. Fershtman and Gneezy (2001) also found a similar phenomenon between the two major ethnic groups within Israeli Jewish society, where Eastern Jews, being economically disadvantaged, were mistrusted by both Ashkenazic Jews and Eastern Jews, although this relationship (unlike that of Palestinians and Israelis or Uyghur and Han) has not been one of violent conflict. In contrast to Hennig-Schmidt et al. (2007) and Fershtman and Gneezy (2001), we find no asymmetric tendency whereby subjects belonging to both groups favor a specific, perhaps more educated, powerful or rich group, which is Han in our case. Both Uyghur and Han subjects are more trusting, trustworthy, and cooperative in an ethnically homogenous group than in a mixed one, and more with identifiable than with unidentifiable others. Our results from the PGG also extend within-group favouritism previously found in terms of interpersonal trust to the case of group cooperation.

Second, our results in the PGG highlight the effect of communication in fostering inter-ethnic cooperation. Among all four conditions in that game, ethnically mixed groups with communication yield the highest level of cooperation. Although it is a well-established result that communication yields higher cooperation in a PGG (Isaac and Walker 1988; Bochet et al., 2006; Brosig et al. 2003), what is novel about our finding on communication is its inter-ethnic context. Moreover, we compare the comparative statics of a move from PGG play in heterogeneous groups without communication to corresponding play (i) in homogenous groups without communication, and (ii) in heterogeneous groups with communication, and find that it is the second transition which yields substantially more cooperation.

Third, studying both TG and PGG interactions in one experiment allows us to contribute to the research frontier of how behaviors in these two games correlate. On the individual level, we find that the levels of both trust and trustworthiness measured in a TG 
significantly positively correlate with the willingness to cooperate measured in a PGG, which echoes the results of Kim et al. (2017). ${ }^{3}$ On the group level, we find that Uyghur subjects show slightly higher trust (trustworthiness) and slightly less willingness to cooperate with others than do Han subjects, and these differences become statistically significant if we use a ratio measure of cooperation relative to trust as our basis for comparison.

The rest of the paper is organized as follows. Section 2 introduces the background of Xinjiang and the two ethnic groups under conflict. Section 3 demonstrates the research design and experimental procedures. Results of the experiment are analysed in Section 4 and discussed in Section 5. Section 6 concludes.

\section{Background}

Xinjiang, China's westernmost and largest province-level administrative division, occupies what has been an interface of world cultural zones for more than two millennia. With a territory bigger than France, Germany, and the U.K. combined, Xinjiang's full name, Xinjiang Uyghur Autonomous Region (XUAR), salutes its largest ethnic group, the Uyghur, who are often depicted as the easternmost of the predominantly muslim, Turkic-speaking peoples (Starr, ed., 2004). Ruled mainly from Beijing since the mid-18 ${ }^{\text {th }}$ century under the Qing Dynasty and succeeding governments, the territory had a large Uyghur majority $(82.7 \%)$ as late as 1945 , with only $6.2 \%$ of the population being Han in that year (Howell and Fan 2011). Seven decades later, under administration of the People's Republic of China, Xinjiang's Han Chinese population edges towards parity with the Uyghur, having risen to

\footnotetext{
${ }^{3}$ Kim et al. (2017) analyze behaviors in a laboratory experiment with U.S. university student subjects and find not only that most subjects condition their contribution in the PGG on their expectation of other group members' contribution levels, but also that both beliefs and public goods contributions are strongly positively correlated with own trusting and trustworthiness in the trust game. Their focus and design differs from ours: by forming PGG groups based on relative trusting or trustworthiness and informing participants about this aspect of group composition, they study how that information influences expectations of cooperation and thereby willingness to cooperate.
} 
$40.5 \%$ in 2010 , versus $45.8 \%$ Uyghur and a remainder consisting of less populous ethnicities including Kazakh, Hui, Kirghiz and Mongolian. ${ }^{4}$

Although individuals of Han and Uyghur ethnicity come from radically different backgrounds, China's leaders have a strong interest in fostering relations of trust and cooperation between the two groups. Xinjiang makes up about one sixth of China's territory, and has $38 \%$ of its coal, $21.5 \%$ of its oil reserves and $23.3 \%$ of its natural gas. ${ }^{5}$ It is also China's gateway to Central Asia, where the country is engaging in vast investment projects in connection with Beijing's “One Belt One Road” program. While encouraging Han migration to the territory, China's policies have usually attempted to convey the appearance, at least, of a benevolent and accommodating attitude towards the Uyghur people, for instance providing economic assistance, more flexible application of birth control policies, affirmative actions on education, and so on. However, tensions between Xinjiang's Uyghur and Han populations flare up from time to time, as attested by the 2009 ethnic riots in Urumqi, in which at least 197 people were killed. ${ }^{6}$

Research and journalistic reports have discovered broad and serious distrust between Hans and Uyghurs, intensifying in recent years. On the one hand, members of China's Han majority have a dominant presence in Xinjiang's economic and political arenas by virtue of Han control of the Chinese Communist Party (CCP), at both central and local levels, and the disproportionate presence of Han in most important positions of government, the military, education, and state-owned companies (Bovingdon, 2010). On the other hand, Uyghurs have become "more and more sensitive, suspicious and anxious" and hold a strong sense of

\footnotetext{
${ }^{4}$ Xinjiang Uyghur Autonomous Region Bureau of Statistics, 2010 Xinjiang Census. https://cpianalysis.org/2016/03/07/spatial-results-of-the-2010-census-in-xinjiang/

5 Resources and Economy Atlas, 2012.

${ }^{6}$ Chinese President Visits Volatile Xinjiang. http://www.nytimes.com/2009/08/26/world/asia/26china.html
} 
distrust toward Han. ${ }^{7}$ Uyghurs complain that the state reserves decision authority and better jobs for Hans only, even when it means importing them from distant China proper (Bovingdon, 2010). Conversely, local Han Chinese complain of Uyghurs' distrust, claiming it to be unjustified. ${ }^{8}$ In one interview, a public health official spoke of difficulty persuading Uyghur peasants to let their children be vaccinated against polio, with many believing a rumor that the sugar cubes can harm the children's future reproduction and that the vaccination program is part of a government effort to control Uyghur population growth.

The mutual distrust might be enhanced by different positions of the two groups in the economic geography of the region. Levels of economic development in the northern, mainly Han, and the southern, mainly Uyghur, parts of Xinjiang, are highly unequal. In 2003, the Han-concentrated oil industry city, Karamay, had a per capita income over ten times that in mainly Uyghur agriculture-heavy prefectures (Zhu and Blachford 2012). Some feel that the series of special policies of "aid for Xinjiang," which are supposed to aid poor regions and thereby alleviate Uyghur dissatisfaction, may backfire and intensify conflicts, since the resources dispensed are believed to go mainly to regions with high proportions of Han residents (Wong and Takeuchi 2013; Bovingdon 2010; Wiemer 2004).

The differing historical and cultural backgrounds of the two ethnic groups may also influence levels of trust and cooperation both within and between them. For centuries, selfidentification in what is now Xinjiang was mainly local, due to the huge distances among the scattered oases (Millward 2007; Rudelson 1997), which lacked overall political centralization. The comparatively independent and scattered lifeways of the Uyghurs contrasts with the steady formation of Han Chinese identity under one bureaucratic empire

\footnotetext{
${ }^{7}$ Ailing Qin, “More Attention is needed on Research of Uyghur's Social Mentality”, (in Chinese “应更重视维 吾尔社会心理研究和疏导”), http://www.2muslim.com/forum.php?mod=viewthread\&tid=766674

${ }^{8}$ The cases in this paragraph were recorded in Zhe Zhang's field interview notes, summer 2016.
} 
after the next since over two thousand years ago. Despite numerous rebellions, uprisings, wars, and periods of political disunity, the Han Chinese sustained an identity linked to a complex of agrarian practices, rules of bureaucracy and taxation, Confucian norms, and language, literature and culture. Although the direct impact of historical political institutions on trust and cooperation is unclear and controversial, ${ }^{9}$ influences operating through the channel of production regime and life-way suggest relatively straightforward conjectures. Talheim et al. (2014) find that rice-growing southern China is more interdependent and holistic-thinking than the wheat-growing north, a difference they attribute to the more intensive collaboration on irrigation, transplantation of seedlings, etc., in rice cultivation. On a more macro scale, the people of both rice and wheat-growing parts of China's densely populated heartland may, by extension, have different characteristics than the less agricultural Altaic-language speakers to China's north and west. Herrmann et al. (2008) find the behavior of Chinese subjects in public goods games to be more abiding of cooperative norms than those at their Middle Eastern and Turkish sites. Observations of Chinese subjects in Tianjin (Fu et al. 2017) and Hangzhou (Markussen et al. 2017) are similarly consistent in showing behaviors more akin to West European than to Middle Eastern and Turkish subject pools. We consider, below, the possibility that Uyghur culture might favor bonds between individuals more than group collaboration, in part due to the importance of long-distance trading in the Tarim Basin and central Asian steppe societies.

Data collection is especially complex and difficult in unstable regions of China such as Xinjiang or Tibet (see Lü, 2015). These may be precisely the sorts of environment in

\footnotetext{
${ }^{9}$ If one extrapolates from views such as those of Weber (1976) or Fukuyama (2011), one might expect members of societies long organized under centralized states to exhibit greater uniformity of and obedience to collective norms. However, Lowes et al. (2015) used a field experiment in the former Kuba Kingdom in present-day Democratic Republic of the Congo and challenge that theory, arguing that centralized formal institutions are associated with weaker norms of rule-following and a greater propensity to cheat for material gain, and that formal institutions can crowd out intrinsic motivations for following the rules.
} 
which simple decision experiments like ours have a strong methodological advantage. Because our protocols draw no attention to our interest in inter-ethnic relations, we were able to conduct laboratory games with the potential to shed light on a problem that local authorities have viewed as too sensitive to be open to objective scholarly inquiry. Applications of the experimental method in China have recently multiplied (Distelhorst and Hou, 2014; Guan and Green, 2006; Gries et al., 2015; Lü et al., 2012), but we know of no study using the method of incentivized decision experiment in Xinjiang. At a further methodological remove, Zhang et al. (2013) report a psychological study that uses a word association task to investigate the implicit trust and discrimination between Uyghur and Han, but their research lacks monetary decision incentives, does not entail direct interactions between members of the two groups, and requires explicit mention of ethnicity. Their findings are consistent with ours in that both Uyghur and Han participants showed significant implicit in-group trust and out-group distrust, but we add many elements, including ability to measure comparative trust in explicit, material terms, and a novel, experimental perspective on the magnitude of outgroup distrust, which turns out to be bounded (in a manner detailed below).

\section{Research Design}

We design our experiment to address three questions on interpersonal trust and group cooperation among and between Uyghur and Han subjects: What effect does the ethnic composition of a group have on trust, trustworthiness and cooperation within the group? Does face-to-face communication enhance inter-ethnic cooperation between Uyghur and Han subjects? How are inclinations to trust, to reciprocate trust (i.e., to be trustworthy), and to cooperate correlated and do Uyghur and Han subjects differ in their willingness to cooperate vs. to trust? The experiment consists of two parts, in both of which explicit cues about 
ethnicity are avoided. In the following subsections, we first describe our subject pool and recruitment procedures, and then explain the two parts of the experiment in detail.

\subsection{Subjects and Procedures}

The experiments were conducted in a public university at Urumqi, capital of Xinjiang. The school has over 8,000 students of which approximately 50\% are Han and 40\% Uyghur. To investigate interpersonal trust and group cooperation among and between Han and Uyghur groups, equal numbers of students of the two ethnicities were recruited in a manner which avoided explicit mention of ethnicity and ethnic balance criteria. Due to the limited equipment availability, the experiment was conducted with pen and paper. Participants made their decisions in an ordinary classroom on campus in June 2016. In all, 15 sessions of the experiment were conducted, each having 8 student participants, 4 Han and 4 Uyghur, for a total of 120 subjects.

Two graduate students from another university were hired as research assistants in the experiments, both being native Uyghur speakers who also speak fluent Mandarin (standard and official Chinese). The consent form and the instruction were read out by the experimenter in Chinese, and the assistants read aloud the Uyghur translation following each paragraph. The written instructions were prepared in both Chinese and Uyghur (in Arabic script), and during the experiment, subjects could ask for explanations or clarifications in Uyghur or Chinese at any time. See Appendix A1 for the English version of the instructions.

The subjects were informed that the objective of the experiment was to study how people make economic decisions under different circumstances. The two parts of the experiment were referred to as entailing "Investment" and "Public Investment" tasks, to minimize the possible connections to themes of trust and cooperation. The fact that ethnic differences and interactions were matters of interest to experimenters was not disclosed to 
subjects, both so as not to influence the results, and because mentioning the topic explicitly would be viewed as highly sensitive and controversial given the local context. ${ }^{10}$

Before the games started, and after the subjects signed and submitted their consent forms, each of the 8 subjects was given a ticket, identifying him or her with a letter from $A$ to $H$, and they would be addressed with the letter in the game, i.e., "Student $\mathrm{A}$ and Student $\mathrm{F}$ are partners in this round". Experimenters randomly assigned the letters for Han subjects $\left(H_{i}\right)$ and Uyghur subjects $\left(U_{i}\right)$ in each session. For example, in one session, the four Uyghur subjects, $U_{1}, U_{2}, U_{3}, U_{4}$, were assigned identification letters $B, D, F$ and $G$, and the four Han subjects were assigned letters $A, D, E$ and $H$. ( $U$ and $H$ equivalents of the subject ID letters $(A \ldots H)$ used in the experiment sessions are for convenience of exposition in our paper, and never mentioned to subjects.) The groupings were randomly drawn before the sessions to facilitate matchings of subjects consistent with the requirements of the research design, while leaving the impression that assignments were determined by letter identifications (and not by other criteria, e.g. ethnicity).

The students were asked to sit in two rows of desks facing one another at a distance of approximately 15 feet (see Appendix B). This was to guarantee that each subject could see the face of a counterpart in the opposite row but could not see that person's decisions on his or her response sheet. Due to the obvious differences in appearance, we anticipated that subjects would fully recognize each identifiable partner's ethnic identity. Follow-up interviews conducted with some subjects after their sessions confirmed that they were aware of having played with "a Uyghur girl” or "a Han boy" in a certain round.

\subsection{The Trust Game (TG)}

\footnotetext{
${ }^{10}$ Since perceptions of the experimenter team and of organizations or institutions it might represent could conceivably also have influenced subjects' behaviors, we note here that co-author Zhe Zhang, the experimenter present at all sessions, described the research to the subjects (with no deception) as being something he was carrying out with cooperation of an economics professor at his university in the United States.
} 
In this part of the experiment, each subject participated in three trust game interactions using the core elements set out by Berg et al. (1995), in which two (possibly anonymous) subjects are paired and provided with equal amounts of money, the $1^{\text {st }}$ mover decides how much if any of the money to send to the second, the money sent is tripled by the experimenter, and the $2^{\text {nd }}$ mover decides how much if any of the tripled money to return to the $1^{\text {st }}$ mover. Deprived of the possibility of entering into an agreement or indeed of communicating at all, the players face a dilemma from the standpoint of self-interested rationality: both could end up having their money doubled if the $1^{\text {st }}$ mover sends her entire endowment and the $2^{\text {nd }}$ mover returns two-thirds of its tripled value; however, a selfish $2^{\text {nd }}$ mover cannot credibly commit to returning anything, and hence a selfish $1^{\text {st }}$ mover who assumes his counter-part to be selfishly rational should send nothing.

We alter the Berg et al. (1995) design principally in that each member of a pair makes the decisions for both roles knowing that which of them will be the $1^{\text {st }}$ and which the $2^{\text {nd }}$ mover will be randomly decided thereafter. This procedure requires that $2^{\text {nd }}$ mover decisions be made for each contingency, in what experimental economists call the "strategy method."11 Also, whereas in Berg et al. (1995) the paired counterparts sit in different rooms and remain anonymous to each other during and after the interaction, two of our three interactions are conducted with full knowledge that the counterpart is the person seated in the opposite position, one of these being an identifiable coethnic partner (Coethnic condition), the other an identifiable partner of the other ethnicity (Outgroup condition). After these two interactions

\footnotetext{
11 Trust game decisions using strategy method are nonetheless similar to those taken sequentially. While some researchers argue that strategy method changes the subjects' perceptions and leads them to process their decisions differently (Güth et al., 2001; Roth, 1995), Brandts and Charness (2011), in a recent survey of the literature, find that the strategy method does not have a systematic effect on experimental results, when compared with the standard direct-response method. And it is beneficial in our design to minimize feedback during the experiment process so that each interaction is fully independent, e.g. two players of the TG might belong to the same group in a later PGG, but neither will have received any information about the past decision of the other nor about any decision thus far of any other participant.
} 
was a third trust game interaction in which the counterpart is an unknown session participant whose identity will never be revealed (Unknown condition). Subjects did not receive feedback between interactions, and it was truthfully explained to them in the instructions that they would learn only their fully aggregated earnings from all interactions described in this and the next section after all interactions had been completed. This feedback structure made it essentially impossible to infer the choice of any given interaction partner, thus imparting a high degree of anonymity of decision despite lack of anonymity with respect to identity in those games in which counterparts were identified to one another visually. ${ }^{12}$

Our subjects wrote down their decisions on paper rather than handling cash, the decisions being denominated in Experimental Currency Units (ECU), and the amount earned being paid out to participants at the end, using the pre-announced conversion rate $1 \mathrm{ECU}=$ $0.8 \mathrm{RMB}$ (roughly $\$ 0.14 \mathrm{US}$ at the time). Each subject additionally received a guaranteed participation payment of 30 RMB (about \$4.60). We deviate slightly from Berg et al. (1995) by having endowments of 9 rather than 10 units (in our case, ECU), in order that returning exactly $1 / 3$ or $2 / 3$ of any tripled sent amount would be available choices while restricting options to the integers. ${ }^{13}$

\footnotetext{
${ }^{12}$ Strictly speaking, the sole circumstances under which behaviors of specific partners could be inferred by a participant would be cases of maximum or minimum aggregate earnings from the experiment as a whole, in which case it might be inferred that all counterparts with whom one had been paired and grouped had been maximally trusting or trustworthy and maximally cooperative, or that all had been entirely untrusting and entirely uncooperative In these hypothetical cases, only identical behaviors could be attributed to all counterparts, without exception. Since neither eventuality transpired for any subject, since subjects were not informed after the fact which roles they had been assigned to be paid off for in their trust game interactions, and since subjects received only a single payment sum for all trust and public goods games combined, no inferences could be made about specific partners, in practice. Of course, we cannot fully rule out that when making decisions in games with identifiable counterparts, some subjects assigned non-zero probability to their actions becoming known due to a logistical error or other circumstance.

${ }^{13}$ These fractions are useful benchmarks since returning $1 / 3$ of the tripled sent amount causes the sender to end up with the same amount she began with $(9 \mathrm{ECU})$, while returning $2 / 3$ causes sender and receiver to earn equal amounts.
} 
The eight subjects were assigned to four pairs, including (ex ante) random pairs of HanHan, Han-Uyghur (equivalently: Uyghur-Han ${ }^{14}$ ), and Uyghur-Uyghur. In the first round, for example, we might have groupings like:

$$
\mathrm{H}_{1} \mathrm{H}_{4}, \mathrm{H}_{2} \mathrm{U}_{1}, \quad \mathrm{U}_{3} \mathrm{U}_{4}, \mathrm{U}_{2} \mathrm{H}_{3} \text { (Round 1) }
$$

In this case, $\mathrm{H}_{1}, \mathrm{H}_{4}, \mathrm{U}_{3}$ and $\mathrm{U}_{4}$ play with coethnics and the other four subjects play with outgroup (non-coethnic) members. In the second round, we would have $\mathrm{H}_{1}, \mathrm{H}_{4}, \mathrm{U}_{3}$ and $\mathrm{U}_{4}$ play with out-group members, and the other two pairs consisting of coethnic members, which assures that all participants play once with a coethnic and once with a subject of the other ethnicity, yet in no interaction giving the impression that the experimenter has intentionally arranged for all to play with a member of their own or of the other ethnicity. For example, a possible grouping for the second interaction would be:

$$
\mathrm{H}_{1} \mathrm{U}_{3}, \mathrm{H}_{2} \mathrm{H}_{3}, \quad \mathrm{U}_{1} \mathrm{U}_{2}, \mathrm{U}_{4} \mathrm{H}_{4}(\text { Round 2) }
$$

For every pair in each round, both players were equally provided with a notionally credited endowment $X$, where $X=9$ ECU. In her decisions as the sender, the subject had to decide on an amount $a$, where $a \in[0,3,6,9]$, to send to the responder. After making the decision without communicating with others, each subject marked the chosen number on the Task-1 response sheet. ${ }^{15,16}$

In her responder role, the subject made a contingent decision for each possible node without knowing the chosen $a$ of her counterpart, thus making three decisions concerning the back-transfer $b_{j} \in[0,1,2, \ldots, 3 a]$. For the contingency $a=3$, she chose back-transfer $b_{1} \in$

\footnotetext{
${ }^{14}$ Recall that assignment to $1^{\text {st }}$ versus $2^{\text {nd }}$ mover roles occurs randomly, after each player makes decisions for both roles.

${ }^{15}$ As Appendix B shows, there was sufficient physical separation between known counterparts so that visual observation of one's choice by the other was impossible. Assistants likewise took care when collecting the marked sheets to prevent observation of choices.

${ }^{16}$ See Appendix A2 for Task-1 and Task-2 response sheets.
} 
$[0,1,2, \ldots, 9] ;$ for $a=6$, back-transfer $b_{2} \in[0,1,2, \ldots, 18]$; and for $a=9$, back-transfer $b_{3}$

$\in[0,1,2, \ldots, 27]$. Responders were not asked to make any choice for the $a=0$ contingency,

since the only option in that case is $b_{0}=0$.

Therefore, in every round of the game, for subject $i$ as $1^{\text {st }}$ mover (sender) in the game, his/her payoff is:

$$
Y_{i}=X-a+b
$$

and for subject $j$ as $2^{\text {nd }}$ mover, his/her payoff is:

$$
Y_{j}=X+3 a-b
$$

where $X=9, a \in[0,3,6,9]$, and $b \in[0,1,2, \ldots, 3 a]$. In all three rounds, no communication between the subjects, whether by word or gesture, was allowed.

By the standard interpretive approach, the amount that a subject chooses to send as $1^{\text {st }}$ mover is an indicator of her trust in the counterpart's "trustworthiness" as a partner (likelihood of returning enough to make trust profitable), noting the absence of a fairness motive for sending in view of the equal endowments. The back-transfer as $2^{\text {nd }}$ mover indicates the responders' reciprocity, trustworthiness, or sense of fairness towards the sender. Under this interpretation, a subject who sent more as $1^{\text {st }}$ mover to a coethnic than to a member of the other group, knowing as she does that the counterpart also knows her ethnicity, seems to show greater trust that the member of her own group will be reciprocally or fairly inclined towards her, whether because she believes her own group to be more reciprocating or fairer in general or because she anticipates within-group favoritism or solidarity. ${ }^{17}$ If we observe the returning of a higher fraction when dealing with a coethnic

\footnotetext{
${ }^{17}$ An additional factor that can't be entirely ruled out is that when weighing less self-advantageous outcomes in which the $2^{\text {nd }}$ mover returns nothing or only a small amount, outcomes to which non-zero probabilities may be attached even if a good return is thought more likely, the fact that tripled money "at least" stays with a coethnic might be viewed as less bad than the monetarily identical outcome in which the recipient is of the other
} 
than with a member of the other group, controlling for amount received, we could reasonably interpret this as indicating such favoritism in fact. We can also compare play within coethnic Uyghur pairs to that within coethnic Han pairs to look for differences in levels of trust and trustworthiness that might stem from differences between the two cultures.

\subsection{The Public Goods Game (PGG)}

The second part of the experiment is based on a standard linear voluntary contribution mechanism or public goods game (PGG). It shares with the TG the properties of a social dilemma: players can be jointly better off if they cooperate, but their private interest rules this out, assuming strict rationality and self-interest. It differs in that moves are simultaneous rather than sequential and that it is usually played in groups larger than two. ${ }^{18}$ The simultaneity feature - participants decide how much to put in the group account independently, without knowing one another's choices, and without ability to condition their choices on those the others make - means that a one-shot game requires only one decision by each in the same symmetric role. And unlike the $1^{\text {st }}$ mover decision in the TG, it is never more profitable to choose a larger rather than a smaller investment. The PGG is widely studied to understand how individuals negotiate the trade-off between self-interest and joint welfare. The traditional game theoretic prediction that rational self-interested individuals will put nothing in the group account is typically contradicted in one-shot interactions, in the early periods of repeated ones, and after unannounced "restarts" of play, with some social scientists and psychologists viewing this as evidence of a human propensity to attempt cooperation when feasible, or to prefer cooperating conditional on others doing so, despite free-riding

ethnicity. "The worst that can happen" may be counted differently, that is, depending on the counterpart' ethnicity. The potential confounding of trust and altruism is discussed, inter alia, by Cox (2004).

${ }^{18}$ In the meta-analysis of 27 linear public goods experiments by Zelmer (2003), average group size is 6.6, with the most common groups sizes being 4 or 5 members. In her regression analysis of share of endowment contributed, group size obtains a small positive coefficient that is marginally significant, at just below the $10 \%$ level. 
incentives (Ledyard, 1995; Gächter and Herrmann, 2008). Studies categorizing players into contrasting behavioral types find the most common one to be individuals who appear to prefer to assign more to the group account the more they expect others to assign (Fischbacher and Gächter, 2010). Inclusion of the PGG interactions in our design gives us a window into possible differences in cooperative propensities within each of the two ethnic groups, their inclinations to cooperate in ethnically mixed groups, and possible differences in cooperation when in the dyadic, sequential trust game versus in the team-played, simultaneous move PGG. ${ }^{19}$

Specifically, we assigned subjects to groups of four, gave each $10 \mathrm{ECU}$, and had them independently decide how many if any ECU to allocate to the group account, which yields a payment of $0.5 \mathrm{ECU}$ to each of the four members for any $1 \mathrm{ECU}$ put in. For simplicity, we limited options and asked each individual to select $C_{i} \in[0,2,4,6,8,10]$; the payoff for member $i$ would be:

$$
Y_{i}=X-C_{i}+0.5^{*} \sum C_{j}
$$

where the summation is over all group members $j$ including $i$, the MPCR (marginal per capita return) is set to 0.5 , and the endowment $X=10 \mathrm{ECU}$. The social optimum and maximum total earnings occur when each group member selects $C_{i}=10$, in which case all earn 20; yet each individual has an incentive to select $C_{i}=0$, since she would earn 25 rather than 20, assuming that the others still selected $C_{j}=10$; however, if all attempt this and put 0 in the group account, each earns 10 in the end.

\footnotetext{
${ }^{19}$ We did not elicit beliefs about how much other group members would contribute nor did we elicit contribution decisions conditional on what others contribute as in Fischbacher et al. (2001) and other studies, in part due to the slower speed of paper-and-pencil logistics, so we are unable to directly disentangle differences in expectations of others' cooperativeness from differences in inclination to contribute at a given expectation. It is nevertheless useful to keep in mind the alternative channels through which identity of group-mates might influence contribution decision, when interpreting the observed results.
} 
There were four PGG rounds in the session. In each round, every subject in each of two four-person groups was equally credited $X=10$ ECU. Each decided how to invest as between a private and a group or public account. All the subjects independently made their decisions and marked the results on a Task-2 sheet at locations sufficiently distant to assure privacy, knowing from past interactions and instructions that there would be no feedback through which their decisions would be identified to one another. ${ }^{20}$

Just as with the TG, although now in groups of four instead of pairs, we had each subject play one PGG round in an ethnically homogeneous group (Homogeneous condition), one in an ethnically mixed (equally split) group (Mixed condition), and one in a group of randomly selected and anonymous others (Unknown condition). In interactions with identifiable others, group membership was called out by letter identifiers, the experimenter making no mention of ethnicity, and subjects reseated themselves where instructed to by the experimenter's calling of letter codes, so as to be able to recognize which participants constituted their group for the interaction. The order of interactions was HomogeneousUnknown-Mixed in the first eight sessions, and Mixed-Unknown-Homogeneous in the remaining seven sessions. A final PGG interaction of each session took place in freshly constituted ethnically mixed groups, ${ }^{21}$ but differed in that members of each four-person group were permitted to engage in a short face-to-face discussion with each other before returning to their desks to mark their individual decision sheets (Communication condition). ${ }^{22}$ There

\footnotetext{
${ }^{20}$ Such privacy and common knowledge hold even in the communication round, since we made sure that subjects returned to their individual seats after talking and marked their sheets in private, which was clearly stated in the instruction.

${ }^{21}$ For completeness, we note that while the PGG mixed group of the interaction without and that with communication were selected to have different participants, we made no systematic attempt to avoid having a subject play with a given other in both a TG and a PGG. Recall again, however, that there was no reporting of results until both sets of games had been completed.

${ }^{22}$ In this final PGG interaction, after the group assignment was announced, all subjects were asked to leave their answer sheets on their own desks and each group gathered in one corner of the classroom. The two groups were about 12 meters away from each other, guaranteeing that no subject would hear or affect those in the other group. They were allowed to communicate, discuss, or debate on their strategies in this PGG interaction in whatever language they feel comfortable with. The communication lasted for 3 to 4 minutes. When time was up,
} 
was no feedback on others' decisions until subjects learned their final aggregated earningswithout breakdown by individual interaction, information as to assigned roles in TG games, report of others' actions, or information on composition of anonymous groups-after all experimental decisions had been made.

We ended each session with the interaction permitting communication in order to investigate its effectiveness in the setting most interesting to us and presumably to China's policy-makers, that of an ethnically mixed interaction. ${ }^{23}$ Although communication does not change the game-theoretic prediction for selfish players in the absence of enforcement mechanisms, it has often been found to substantially raise cooperation in laboratory play when the medium is spontaneous verbal interaction (as opposed to selection of numerical or pre-packaged messages) and especially when face-to-face (Isaac and Walker, 1988; Bochet et al., 2006; Brosig et al., 2003). Since there is no feedback from earlier choices, we can also in principle make an interesting comparison between comparisons: taking the PGG played in an ethnically mixed group without communication (PGG round 1 or 3) as a starting point, we can ask which of the following two changes - (a) substituting ethnic homogeneity for heterogeneity (still without communication, round 3 or 1), or (b) adding communication (while retaining ethnic heterogeneity, round 4)-increases cooperation more? If cooperation is higher under ethnic homogeneity without communication than under ethnic heterogeneity with communication, then we may tentatively conclude that ethnic mistrust is quite strong among our subjects, while if adding communication produces more cooperation than does eliminating ethnic heterogeneity, we can tentatively conclude that at least among these

\footnotetext{
the experimenters would ask the subjects to stop talking, go back to their own desks, and make decisions independently without being seen by others.

${ }^{23}$ Observing ethnically homogenous groups interact with communication would also have been interesting but had to be foregone because having two interactions with communication would have required implementation in both orders to be sure of ruling out (or in) order effects. This could not be satisfactorily carried out within our constraints of time and sample size.
} 
students of an ethnically mixed school, ethnic differences are not so severe an impediment to working together. ${ }^{24}$

\subsection{Exit Survey}

After the TG and PGG portions of each session ended and before the experimental outcomes were revealed, an exit survey was distributed to the students, asking general information including age, gender, family income, parents' education, etc. Two widely used questions from the World Value Survey were also included at the end. See Appendix A3 for the survey questionnaire in English.

To sum up, we illustrate the timeline of a typical session in Figure 1 below. Note that only the order of PGG conditions 1 and 3 differs between the first eight (order A) and the last seven (order B) sessions.

A

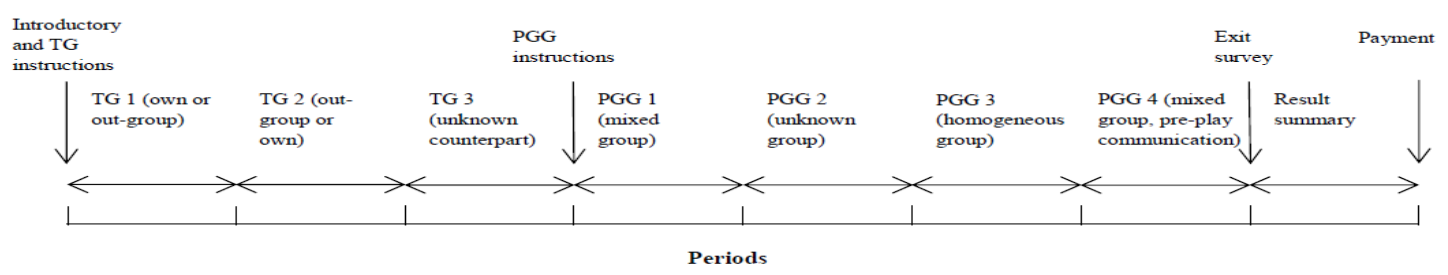

Mixed-Unknown-Homogeneous-Communication Order Sessions

$\mathbf{B}$

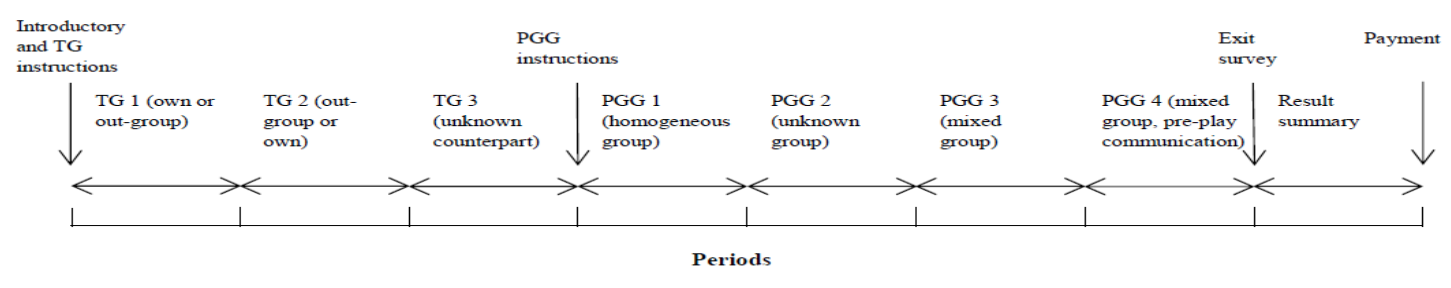

Homogeneous-Unknown-Mixed-Communication Order Sessions

Figure 1. Timeline of the experiment

\footnotetext{
${ }^{24}$ A small potential issue is that while we vary the homogeneous-mixed vs. mixed-homogeneous ordering of interactions across sessions, the interaction with communication is always last. Without feedback, however, we view the problem as minor. The existing order is preferred in our view, when only one is possible, because communication can contaminate any no-communication interactions that follow it by altering participants' understandings of the nature of the game. We note that having representation of multiple ethnicities is the norm for post-secondary education in Xinjiang. The degree to which the students are able to cooperate in our task might thus be seen as one crude indicator of the success of the policy of ethnic mixing with respect to government-sought defusing of tensions between the groups.
} 


\section{Results}

\subsection{Descriptive}

A total of 120 students participated in the experiment, of whom 60 were Han and 60 Uyghur. Gender shares were nearly equal overall (58 females and 62 males), with somewhat less equal but partly offsetting parities by group (55\% male among the Uyghur subjects, 55\% female among the Han). Subjects' ages varied from 18 to 23 , with a mean of 19.9 years. About $89 \%$ of the students were at the end of their first year in the three-year college, and others were in their second year $\left(2^{\text {nd }}\right.$ year $){ }^{25}$ The majority of the students lived in Xinjiang before college, with only 32 of the 120 having lived outside of Xinjiang for at least six months sometime in the past (Lived outside of Xinjiang > 6 Months), the majority (24) of the latter being ethnic Han. ${ }^{26}$ Most of the students were not from highly educated families: only $10 \%$ have at least one parent that holds a college degree or above (Parent w/ college degree). Subjects were asked to self-evaluate and rank the position of their family's annual income in the local city or county (Family income), ${ }^{27}$ and $58 \%$ of students chose about average; $31.6 \%$ of Uyghur students rank their families above average, while only $10 \%$ of Han students do so.

The average total earning from the experimental interactions was $100.9 \mathrm{ECU}$, so on average participants earned $100.9 * 0.8+30=110.7 \mathrm{RMB}$, including the $30 \mathrm{RMB}$

\footnotetext{
25 No third-year students participated because most work away from the campus as interns.

${ }^{26}$ We asked about past residence outside of Xinjiang in an exit question and use it as a control in some of our regression analysis because members of Han families that moved to Xinjiang during the student's lifetime or have otherwise spent time in both Xinjiang and China proper could conceivably view both Uyghurs and more locally-rooted Han differently than the latter, while members of Uyghur families that have also lived outside the region might conceivably be more cosmopolitan or otherwise differ in outlook from less travelled Uyghur students. It is beyond the scope of our study to investigate these matters in detail, however, e.g. we only use a binary control Lived outside Xinjiang > 6 months and do not further distinguish, for instance, at what age a student of Han ethnicity moved to Xinjiang, how many generations the family of a Han student has lived in Xinjiang, or exactly where the time outside of Xinjiang was spent (we presume this to be China proper but cannot rule out rare alternatives like time in neighboring western regions, say Inner Mongolia, or in other countries, such as Kazakhstan).

27 The rank options are: a) Top 10\%; b) Above average (10\% - 40\%); c) About average (40\% - 60\%); d) Below average (60\%-90\%); and e) Bottom (under 90\%).
} 
participation fee. As Table 1 shows, Uyghur participants earned slightly more than did Han students in both sets of games, but the differences for each set of games and overall are statistically insignificant (trust games, $p=0.8131$; public goods games, $p=0.1101$; combined earnings, $p=0.3567){ }^{28}$

Table 1. Average earnings in $T G$ and $P G G$

\begin{tabular}{cccc}
\hline & TG & PGG & Total \\
\hline Uyghur & 40.08 & 61.67 & 101.75 \\
Han & 39.85 & 59.70 & 99.55 \\
\hline Pooled & 39.97 & 60.68 & 100.65 \\
\hline
\end{tabular}

Notes: Earning unit in the table is in ECU.

In the exit survey, subjects were asked to respond to the question "Generally speaking, would you say that most people can be trusted or that you can't be too careful in dealing with people? (WVS trust). ${ }^{, 29}$ Uyghur and Han students answered quite differently, with $78 \%$ of Han vs. only $35 \%$ of Uyghur students choosing "Most people can be trusted" ( $p$ $<0.0001) .{ }^{30}$ On the question "How satisfied are you with your life as a whole?

(Satisfaction)" with a scale where $1=$ Very Dissatisfied and $10=$ Very Satisfied, Uyghur students tended to choose significantly higher responses $($ mean $=8.3)$ than Han students did $($ mean $=6.6, p<0.0001){ }^{31}$

\subsection{Trust Game}

\subsection{1 $1^{\text {st }}$ mover decisions}

\footnotetext{
28 Two-sided Mann-Whitney test.

29 This so-called "generalized trust" question is included in the General Social Survey and the World Values Survey, and widely used by social scientists to study trust. The extent to which survey and experimental measures of trust are capturing the same thing has also been a focus of debate, for example Naef and Schupp (2009).

30 Two-sided Mann-Whitney test.

31 Two-sided Mann-Whitney test.
} 
In this subsection, we analyze the $1^{\text {st }}$ mover decisions, i.e., how much to send to the $2^{\text {nd }}$ mover, in the TG, which serve as the primary measure of trust in our research. Here we focus on the differences in amount sent across conditions. We save the Han-Uyghur comparison of $1^{\text {st }}$ mover behaviors for Subsection 4.5, where we study it alongside of the corresponding comparison of PGG behaviors.

Figure 2 shows the average amount subjects sent as $1^{\text {st }}$ movers in the trust game under each interaction condition: interacting with an identifiable subject of the same ethnicity (Coethnic), with an identifiable subject of the other ethnicity (Outgroup), and with an unknown participant who is to be randomly selected (Unknown). On average, subjects sent 5.25 of their 9 ECU, about $58.3 \%$, or about half of one standard deviation above the average sending of $50.9 \%$ in Johnson and Mislin's meta-analysis or 84 studies. $^{32}$ From Figure 2, we see that subjects of both ethnicities sent more money when paired with an identifiable coethnic than with one of the other ethnic group, and more money to the latter than to an unknown partner. To see whether such differences are statistically significant, we performed Wilcoxon matched pair tests within each ethnic group and for subjects of the two ethnic groups pooled together. The results show that, when the paired partner was identifiable, both ethnicities sent significantly more money to coethnic than to out-group members, although the significance level of the difference is greater for Uyghur $(p=0.0206)$ than for Han subjects $(p=0.0961)$. In addition, interestingly, participants of both ethnicities sent more money to an identifiable out-group member than to an entirely anonymous counterpart, although this difference is statistically significant only for the Han participants $(p=0.0037)$.

\footnotetext{
32 Several factors those authors find significant positive predictors of sending may help to explain the relatively high sending of our subjects: counterparts are definitely real, subjects play both roles, return decisions are made using strategy method. That our subjects were seated opposite their counterparts and most interactions, thus reducing social distance, might also be a contributing factor. Finally, the fact that sending $50 \%$ is not an option for any individual subject or interaction in our design, which permits sending only $0 \%, 1 / 3,2 / 3$, and $100 \%$ of the endowment, may have affected average sending.
} 
When Uyghur and Han subjects are pooled together, on average they sent significantly more money to coethnic counterparts than to out-group ones $(p=0.0046)$ and significantly more to out-group counterparts than to unknown ones $(p=0.0053)$.
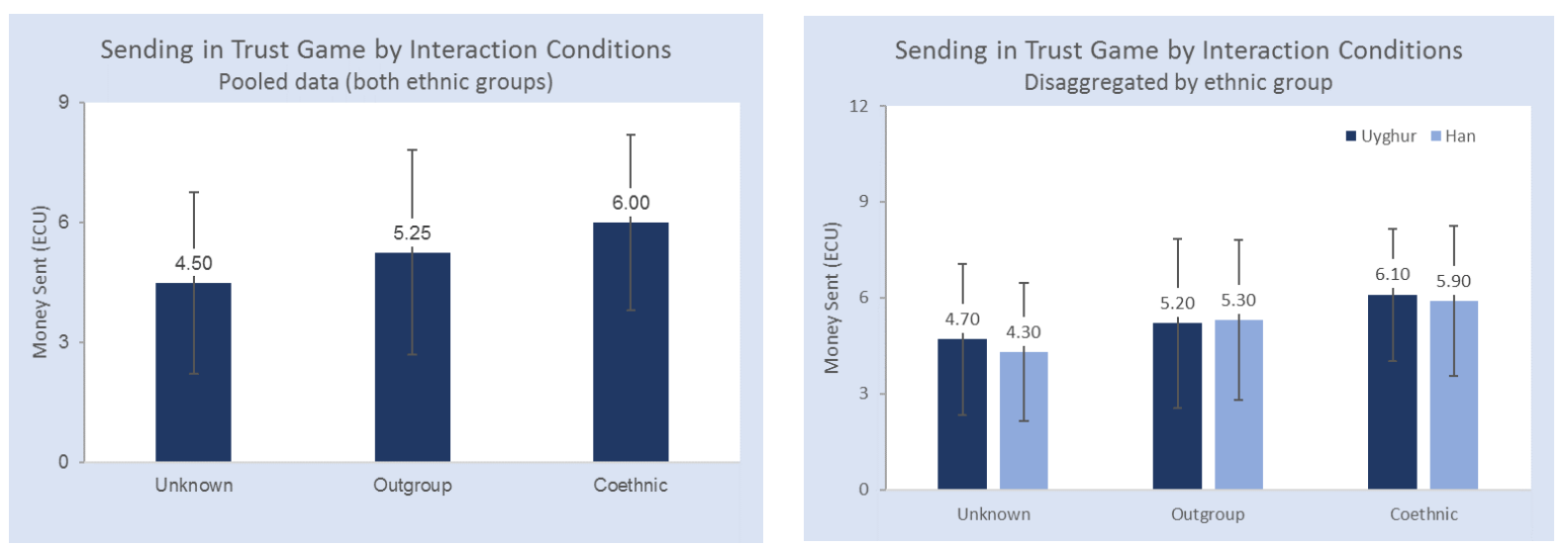

Figure 2. Amount sent in trust game by Interaction Conditions

To investigate the effects of one's demographic factors and attitudes elicited in the exit survey on her amount sent as the $1^{\text {st }}$ mover in the trust game, we run several regressions. The results from OLS estimations clustering by sessions are shown in Table 2 below. As a robustness check, we also run regressions with individual fixed or random effects (see Appendix C Table A1), the results of which are quite similar to the OLS estimates and thus omitted here. Note that in column (3) and (4), we include not only the Lived outside of Xinjiang > 6 Months variable, but also its interaction with the Han indicator in order to explore the possibility that exposure to other areas affects Han and Uyghur subjects differently.

Table 2. Amount sent in TG regressions

\begin{tabular}{lcccc}
\hline & $(1)$ & $(2)$ & $(3)$ & $(4)$ \\
\hline \multirow{4}{*}{ Coethnic } & & & & \\
& $1.500^{* * *}$ & $1.500^{* * * *}$ & $1.487 * * *$ & $1.487 * * *$ \\
& $(0.287)$ & $(0.288)$ & $(0.291)$ & $(0.292)$ \\
Outgroup & $0.750 * * *$ & $0.750 * * *$ & $0.731 * * *$ & $0.731 * * *$ \\
& $(0.205)$ & $(0.205)$ & $(0.217)$ & $(0.217)$
\end{tabular}




\begin{tabular}{|c|c|c|c|c|}
\hline Male & $\begin{array}{c}0.539 \\
(0.326)\end{array}$ & $\begin{array}{l}0.579 * \\
(0.305)\end{array}$ & $\begin{array}{c}0.445 \\
(0.289)\end{array}$ & $\begin{array}{c}0.367 \\
(0.287)\end{array}$ \\
\hline Han & $\begin{array}{l}-0.113 \\
(0.332)\end{array}$ & $\begin{array}{l}-0.386 \\
(0.409)\end{array}$ & $\begin{array}{c}-0.693 \\
(0.401)\end{array}$ & $\begin{array}{l}-0.695 \\
(0.410)\end{array}$ \\
\hline $\begin{array}{l}\text { Family } \\
\text { income }\end{array}$ & & & $\begin{array}{c}-0.213 \\
(0.205)\end{array}$ & $\begin{array}{c}-0.213 \\
(0.208)\end{array}$ \\
\hline $\begin{array}{l}\text { Lived outside } \\
\text { of Xinjiang } \\
>6 \text { Months }\end{array}$ & & & $\begin{array}{c}0.797 \\
(0.570)\end{array}$ & $\begin{array}{l}0.989 * \\
(0.544)\end{array}$ \\
\hline $\begin{array}{l}\text { Han } \times \text { Lived } \\
\text { outside of } \\
\text { Xinjiang } \\
>6 \text { Months }\end{array}$ & & & $\begin{array}{c}-0.0424 \\
(0.791)\end{array}$ & $\begin{array}{c}-0.206 \\
(0.762)\end{array}$ \\
\hline $\begin{array}{l}\text { Parent w/ } \\
\text { college } \\
\text { degree }\end{array}$ & & & $\begin{array}{l}-0.280 \\
(0.602)\end{array}$ & $\begin{array}{l}-0.360 \\
(0.533)\end{array}$ \\
\hline Satisfaction & & & $\begin{array}{c}-0.117 \\
(0.0670)\end{array}$ & $\begin{array}{c}-0.0968 \\
(0.0713)\end{array}$ \\
\hline WVS trust & & $\begin{array}{c}0.639 \\
(0.367)\end{array}$ & $\begin{array}{c}0.585 \\
(0.338)\end{array}$ & $\begin{array}{l}0.676 * \\
(0.344)\end{array}$ \\
\hline $2^{\text {nd }}$ year & & & & $\begin{array}{c}1.320 * * \\
(0.471)\end{array}$ \\
\hline Constant & $\begin{array}{c}4.278 * * * \\
(0.317)\end{array}$ & $\begin{array}{c}4.032 * * * \\
(0.339)\end{array}$ & $\begin{array}{c}5.630 * * * \\
(0.821)\end{array}$ & $\begin{array}{c}5.325 * * * \\
(0.896)\end{array}$ \\
\hline Observations & 360 & 360 & 357 & 357 \\
\hline R-squared & 0.078 & 0.092 & 0.114 & 0.140 \\
\hline
\end{tabular}

Each regression in Table 2 pools the decisions of each participant in all three TG interactions.

The OLS estimates of the coefficients on Coethnic and Outgroup in Table 2 confirm the results of previous non-parametric tests. With all the demographic covariates and survey measures controlled in column (4), subjects sent significantly more money, 0.756 ECU to be specific, to their identifiable coethnics than to out-group members ( $p=0.0077$, nested F-test), and least to partners who were totally unknown (0.731 ECU less than to out-group ones, $p<$ 0.010, two-sided t- test). Students who were in their $2^{\text {nd }}$ year sent significantly more money to paired partners, a possible explanation being that with longer education and greater sense of connection with fellow students, $2^{\text {nd }}$ year students trust others more than their freshmen 
counterparts. ${ }^{33}$ Experience living outside of Xinjiang has a marginally positive effect that does not seem contingent on being ethnically Han.

Given that both the amount sent in the TG and the answer to the general trust question in the World Value Survey are supposed to measure trust, one may expect the coefficient of WVS trust to be significantly positive. However, previous studies have shown mixed results (see Sapienza et al., 2013 for more discussions on this). While Glaeser et al. (2000) and Lazzarini et al. (2003) find that survey trust doesn't correlate with game trust, Fehr et al. (2003) and Bellemare and Kroeger (2007) find the two do correlate. Relative to the existing literature, our result is slightly more on the side with Fehr et al. (2003) than that of Glaeser et al. (2000), since we observe a positive coefficient on survey trust in Table 2 column (4), although it is only marginally significant. Another interesting observation is that while on average, Uyghurs are less trusting than Hans when judged by survey question answers (see Section 4.1), they are no less (if not more) trusting measured by amount sent in the TG (see the insignificant negative coefficients on Han inTable 2). Combing the above two observations, we conclude that (i) survey trust fails badly to predict game trust at the level of comparing the two ethnicities, but (ii) survey trust marginally succeeds in predicting game trust at the level of individuals, once controlling for ethnicity and other factors.

\subsection{2 $2^{\text {nd }}$ mover decisions}

In the previous subsection, we've looked only at decisions taken as the $1^{\text {st }}$ mover in the TG. The $2^{\text {nd }}$ mover decisions in this game are interesting in their own right, in part because they may reflect a sense of obligation or fairness towards the counterpart, which might differ depending on ethnicity and ethnic matching. Also, even if we had no interest in those factors for their own sake, what expectations subjects had about their counterparts

\footnotetext{
33 Conceivably, greater comfort with non-coethnics plays a role, but detailed statistical analysis of the matter is omitted since $2^{\text {nd }}$ year students account for only $11 \%$ of our subjects.
} 
when making their $1^{\text {st }}$ mover decisions are probably important to those choices, and $2^{\text {nd }}$ mover behavior has been found to be strongly correlated with expectations of others' behaviors, in other studies, e.g. Sapienza et al. (2013). In this subsection, we analyze the $2^{\text {nd }}$ mover decisions in two respects: how much was returned as a proportion of the amount received, and how often subjects returned 0 .

Figure 3 shows the average percentage of received tripled amount which subjects returned as $2^{\text {nd }}$ mover under all three interaction conditions. Overall, subjects returned about $43 \%$ of any tripled amount received, above the average of $36.5 \%$ in Johnson and Mislin's meta-analysis by about $69 \%$ of one standard deviation. On average, we see that members of both ethnic groups sent back more to a coethnic partner than to a member of the out-group ( $p$ $=0.0382$ for Uyghur, and $p=0.0135$ for Han, two-sided Wilcoxon paired tests), and more in the latter case than to a randomly chosen unidentifiable (unknown) counterpart $(p=0.0008$ for Uyghur, and $p=0.0036$ for Han, two-sided Wilcoxon paired tests). In every condition, Uyghur subjects returned more money on average than did Han ones, although the difference between Uyghur and Han behaviors is statistically significant only for the Outgroup condition and marginally so for Unknown condition $(p=0.2459,0.0322,0.0580$ for Coethnic, Outgroup and Unknown respectively). ${ }^{34}$ The overall proportion returned is $46 \%$ for Uyghur subjects and $40 \%$ for Han, and these shares are significantly different at the $10 \%$ level in a two-sided Mann-Whitney test $(p=0.0512)$. In fact, to a Han sender, a Uyghur receiver returns as much as a Han receiver does ( $p=0.5832$, two-sided Mann-Whitney test).

\footnotetext{
34 Two-sided Mann Whitney tests. Note that we report the average of all choices made on a contingent basis, rather than focusing on those choices that were randomly selected and paid out ex post. The latter choices are basically irrelevant for our purposes, because with subjects themselves not learning the outcomes until the end of their session, which choice was paid out for ex post could not have influenced behaviors. In practice, average paid out choices are quite similar to average overall choices. Our use of all contingent choices rather than only the implemented ones means that between-group differences in returning behavior are in no way affected by the sending decisions and thus by the influence of identity pairing on those decisions.
} 

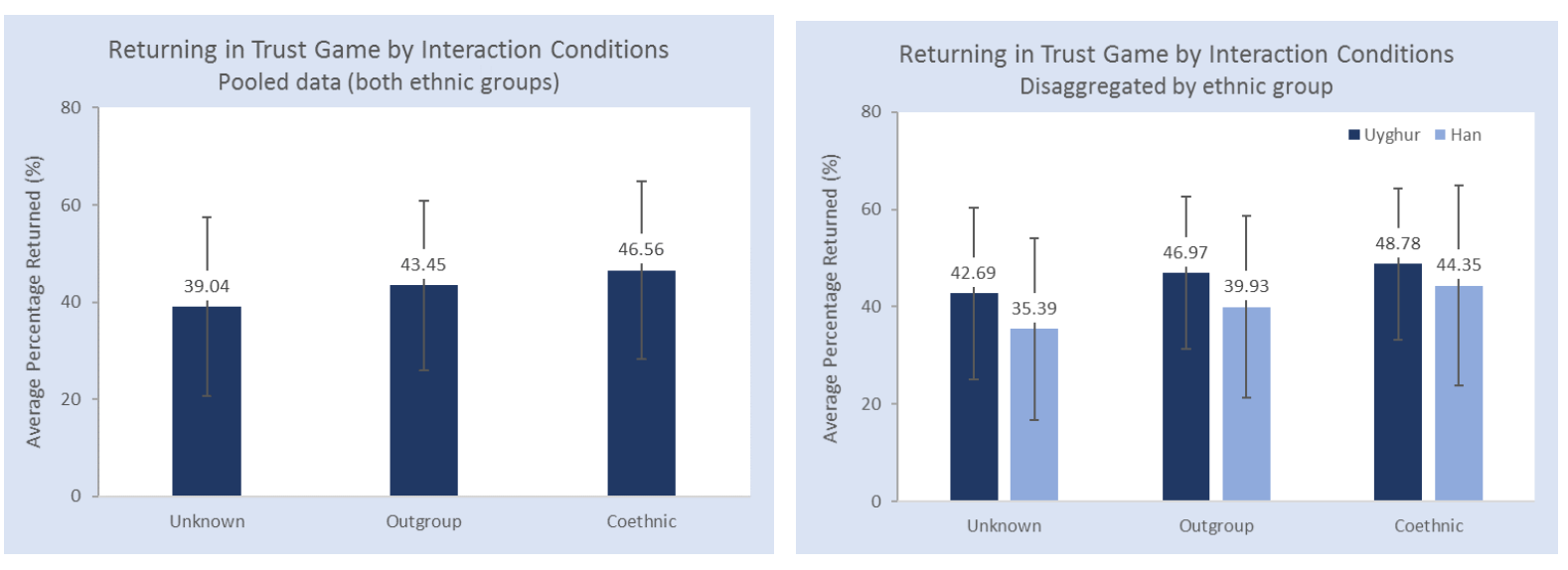

Figure 3. Average percentage returned in TG by interaction conditions

To put the $2^{\text {nd }}$ mover decisions in perspective, recall that all money sent would be tripled by the experimenter, so if the $2^{\text {nd }}$ mover returned at least $1 / 3$ of the tripled funds, the $1^{\text {st }}$ mover was no worse off for having sent money, while if the $2^{\text {nd }}$ mover returned $2 / 3$, both parties earned equal totals in the interaction. Also recall that the prediction for a strictly selfinterested actor is to return nothing. Since the average proportion returned by all participants was around $43 \%$, with the corresponding shares for both Han and Uyghur $2^{\text {nd }}$ movers' both being substantially above $1 / 3$ even in interactions with a counterpart known to be of the other ethnicity, it seems that fairly strong norms of reciprocity, trustworthiness or fairness exist among these subjects. A risk-neutral $1^{\text {st }}$ mover with correct expectations about average $2^{\text {nd }}$ mover behavior should, with our subject pool, have sent her entire $9 \mathrm{ECU}$ if her goal was to maximize her earnings. Of course, some participants may have been risk averse, in which case the possibility of receiving nothing in return might weigh more heavily in their calculations.

For each subject, there were nine return decisions to make as the $2^{\text {nd }}$ mover, and theoretically the truly selfish player would return 0 in every one of them. However, in reality, no subject returns 0 under more than six out of nine contingencies, and only seven subjects return 0 more than 3 times (see Appendix C Figure A1 for the complete distribution of frequencies of returning 0 among subjects), with the average subject returning zero in less 
than a single contingency. In particular, Han receivers return nothing 0.75 times out of nine while Uyghur receivers do so only 0.27 times, the difference being significant at the $5 \%$ level with a two-sided Mann-Whitney test $(p=0.0184)$. To further explore the ethnic differences in the frequency of returning 0 , we disaggregate conditions (while pooling the three contingencies under each condition) and find that Han subjects return 0 significantly more often than do Uyghurs in the Coethnic $(p=0.0481)$ and Outgroup $(p=0.0284)$ conditions, and marginally significantly more than do Uyghurs when facing an Unknown $1^{\text {st }}$ mover $(p=$ 0.0675). When we look at what proportion of subjects return 0 under each of the nine contingencies, we see subjects tend to return 0 much more often when the $1^{\text {st }}$ mover sent only 3 ECU than under the other contingencies - echoing a finding in the literature that being less trusted tends to lead to being less trustworthy_although Figure 4 shows that this is driven primarily by Han receivers' choices. Han receivers return 0 more often than Uyghurs when 3 ECU are sent, no matter whether the condition is Coethnic, Outgroup or Unknown ( $p=$ 0.0690, 0.0085, 0.0235, two-sided Mann-Whitney tests). ${ }^{35}$
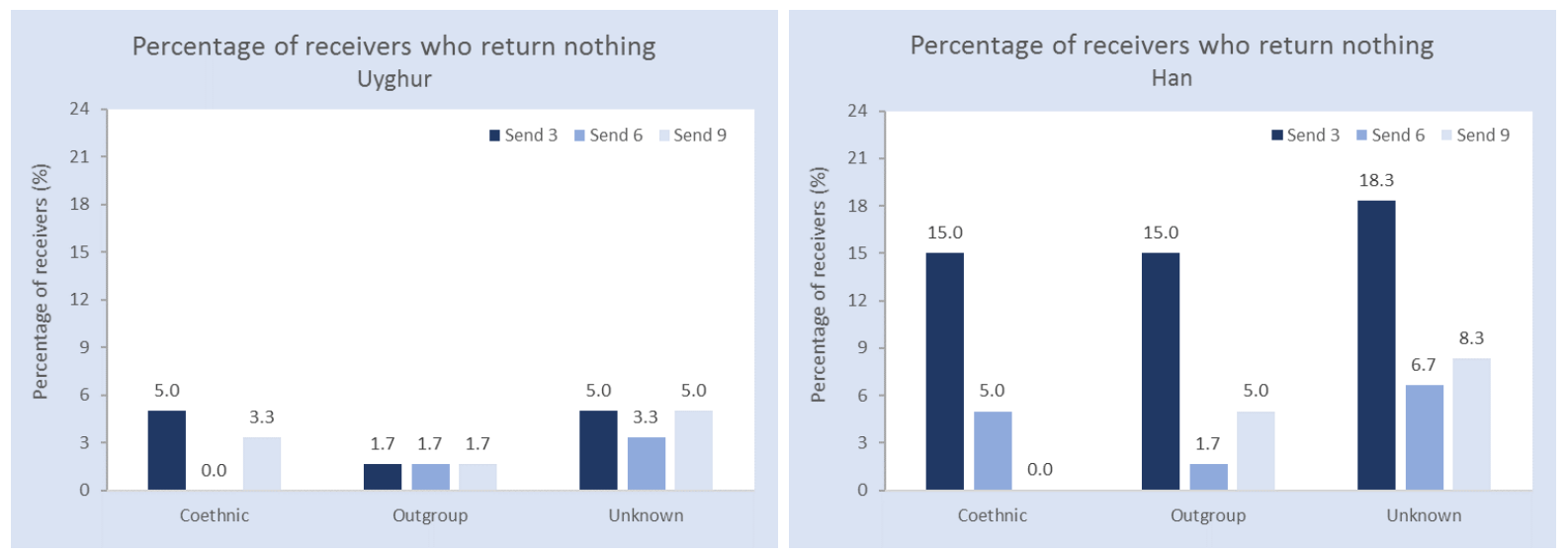

Figure 4. Percentage of receivers who return nothing in TG

\footnotetext{
${ }^{35}$ Similar results hold when looking at subjects who return less than $1 / 3$ (including 0 ), with $p=0.0510,0.0190$, 0.0560, respectively. See Appendix C Figure A2 - A3 for corresponding graphs.
} 
Combing the above analyses based on both the average percentage returned and the number of 0 returns, we can say that Uyghur subjects are overall more trustworthy as the $2^{\text {nd }}$ movers in the TG, and that Han subjects differentiate their $2^{\text {nd }}$ mover responses to out-group vs. coethnic members more than Uyghur subjects do. The latter is somewhat reminiscent of the finding in Hennig-Schmidt et al. (2007) that Palestinian subjects did not discriminate between other Palestinian versus Israeli subjects in their returning behavior, whereas Israeli subjects did return higher proportions to Israeli than to Palestinian counterparts. ${ }^{36}$

\subsection{Public Goods Game}

In this subsection, we analyze the amount contributed by each subject in the PGG, which is our measure of his or her willingness to cooperate in the group. We study the effects of different interaction conditions, i.e., the ethnic composition in the group and the opportunity of pre-play communication, with non-parametric tests and OLS regressions.

The overall average contribution (averaged over all four conditions) is 5.30 of 10 ECU, with Uyghur and Han subjects contributing averages of 5.02 and 5.59 respectively, which are not significantly different from each other $(p=0.2046$, two-sided Mann-Whitney test). ${ }^{37}$ With regard to our own focus, Figure 5 shows that average contributions vary across conditions quite similarly to the pattern in the TG; that is, subjects of both ethnic groups contributed the most when in an identifiable homogeneous group of coethnics (Homogeneous), less when in an ethnically mixed group of identifiable individuals (Mixed), and least when in groups of randomly selected, unidentifiable (unknown) individuals

\footnotetext{
${ }^{36}$ In Hennig-Schmidt et al. (2007), Israeli responders back-transfer $40.1 \%$ to their coethnics and $35.6 \%$ to Palestinian partners, while Palestinian responders back-transfer $49.1 \%$ to their coethnics and $51.1 \%$ to Israeli partners. Our results differ from those of Hennig-Schmidt $e t$ al. in that there is a much larger difference in $1^{\text {st }}$ mover behaviors of the Palestinian and Israeli subjects in their trust game than in those of our Uyghur and Han subjects in ours. We note that the Hennig-Schmidt et al. study has fewer subjects than our study and that members of the different groups took part at different sites and with explicit reference to identity, rather than at the same site and without explicit reference to identity, as in our study. A larger follow-up study by some of the same authors does not report comparisons of returning behaviors.

${ }^{37}$ According to Zelmer (2003), these numbers are in the standard range for one-shot PGG and for first period choices in finitely repeated PGG.
} 
(Unknown), and these differences are all statistically significant for both Uyghurs and Hans and when all subjects are pooled together $(p=0.0092,0.0003$ respectively for Uyghur; $p=$ $0.0061,0.0057$ respectively for Han; $p=0.0002, p<0.0001$ respectively when Uyghur and Han are pooled, Wilcoxon tests). Moreover, in an ethnically mixed group with pre-play communication (Communication), subjects tend to send significantly more than even in an ethnically homogeneous group $(p<0.0001$ for Uyghur; $p<0.0001$ for Han; $p<0.0001$ when Uyghur and Han are pooled, Wilcoxon tests).

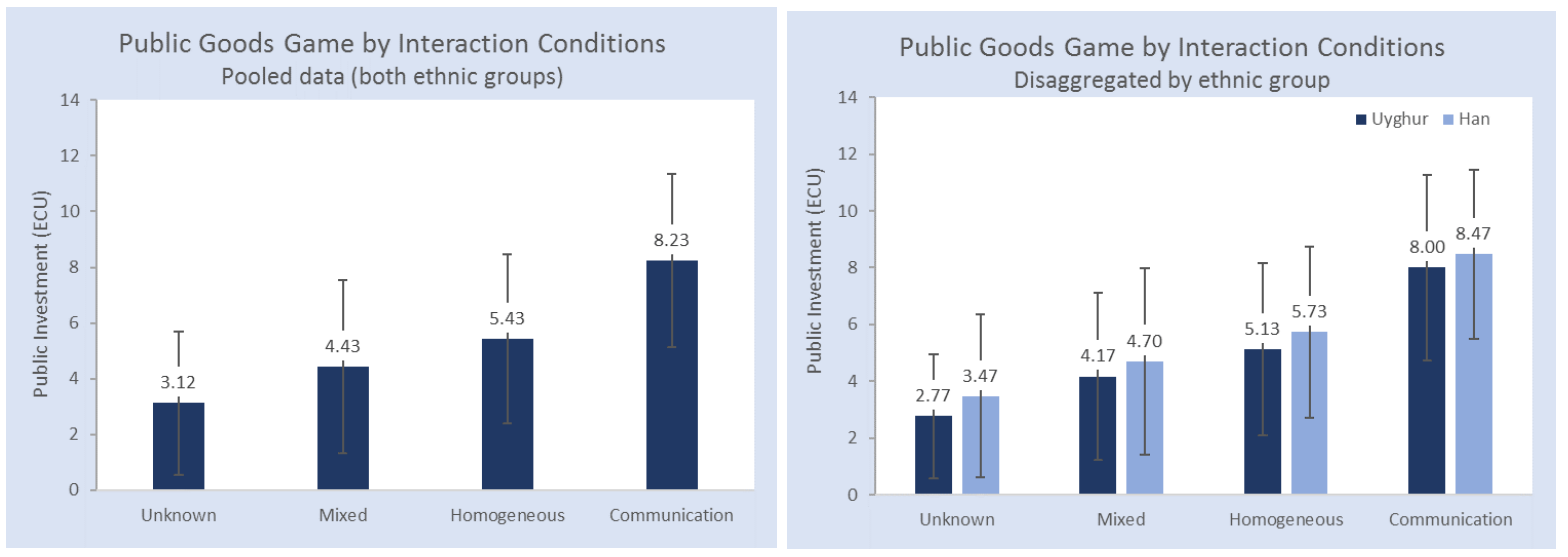

Figure 5. Amount Contributed in PGG by Interaction Conditions

As in Subsection 4.2.1, we also run several OLS regressions with different specifications to see the effects of interaction conditions and demographic covariates on the contributed amount in the PGG. The results are shown in Table 3 (see Appendix C Table A2 for regressions with individual fixed or random effects for a robustness check). We control for a possible order effect by including an Order dummy variable that is set to 1 for sessions of Mixed-Unknown-Homogeneous-Communication order and 0 for sessions of Homogeneous-Unknown-Mixed-Communication order; the results indicate that the order did not influence results significantly. In addition, since each subject played four public goods games sequentially, one under each condition, we check whether there is any trend in her investment behavior over time. For example, subjects may learn to invest more (or less) after previous plays, although such a learning effect seems unlikely in our experiment due to the 
lack of feedback. We use Interaction number $\in 1,2,3,4$ to denote that the observation was

from the $n^{\text {th }}$ game played by the subject. This variable's insignificance in every regression model suggests that there is no (linear) trend over time in subjects' investment in the public goods games (the result is unaffected by leaving out the communication interaction, in columns (5) - (8)). Finally, we add an ethnicity dummy, Han, in models (2) - (4) and (6) (8), as well as interactions between this dummy and the Mixed condition, with having lived outside of Xinjiang, and finally a triple interaction of the three factors. None of these variables obtain statistically significant coefficients, nor is the Han variable significant when some or all of the interaction terms are omitted (results available on request). ${ }^{38}$

Table 3. Amount invested in PGG regressions

\begin{tabular}{|c|c|c|c|c|c|c|c|c|}
\hline & (1) & (2) & (3) & (4) & (5) & (6) & (7) & (8) \\
\hline Homogeneous & $\begin{array}{c}2.312 * * * \\
(0.314)\end{array}$ & $\begin{array}{c}2.315 * * * \\
(0.318)\end{array}$ & $\begin{array}{c}2.315 * * * \\
(0.319)\end{array}$ & $\begin{array}{c}2.315 * * * \\
(0.320)\end{array}$ & $\begin{array}{c}2.312 * * * \\
(0.314)\end{array}$ & $\begin{array}{c}2.315 * * * \\
(0.319)\end{array}$ & $\begin{array}{c}2.315 * * * \\
(0.321)\end{array}$ & $\begin{array}{c}2.315 * * * \\
(0.321)\end{array}$ \\
\hline Mixed & $\begin{array}{c}1.321 * * * \\
(0.258)\end{array}$ & $\begin{array}{c}1.249 * * * \\
(0.265)\end{array}$ & $\begin{array}{c}1.249 * * * \\
(0.266)\end{array}$ & $\begin{array}{c}1.249 * * \\
(0.266)\end{array}$ & $\begin{array}{c}1.321 * * * \\
(0.258)\end{array}$ & $\begin{array}{c}1.296 * * * \\
(0.259)\end{array}$ & $\begin{array}{c}1.296 * * * \\
(0.261)\end{array}$ & $\begin{array}{c}1.296 * * * \\
(0.261)\end{array}$ \\
\hline Communication & $\begin{array}{c}4.983 * * * \\
(0.512)\end{array}$ & $\begin{array}{c}4.932 * * * \\
(0.509)\end{array}$ & $\begin{array}{c}4.932 * * * \\
(0.510)\end{array}$ & $\begin{array}{c}4.932 * * * \\
(0.511)\end{array}$ & & & & \\
\hline Order & & & & $\begin{array}{c}0.989 \\
(0.566)\end{array}$ & & & & $\begin{array}{c}0.602 \\
(0.579)\end{array}$ \\
\hline Interaction number & $\begin{array}{l}0.0670 \\
(0.144)\end{array}$ & $\begin{array}{l}0.0718 \\
(0.150)\end{array}$ & $\begin{array}{l}0.0718 \\
(0.150)\end{array}$ & $\begin{array}{l}0.0718 \\
(0.150)\end{array}$ & $\begin{array}{l}0.0670 \\
(0.144)\end{array}$ & $\begin{array}{l}0.0727 \\
(0.150)\end{array}$ & $\begin{array}{l}0.0727 \\
(0.151)\end{array}$ & $\begin{array}{l}0.0727 \\
(0.151)\end{array}$ \\
\hline Male & & $\begin{array}{l}-0.413 \\
(0.253)\end{array}$ & $\begin{array}{c}-0.420 * \\
(0.233)\end{array}$ & $\begin{array}{c}-0.381 * \\
(0.212)\end{array}$ & & $\begin{array}{l}-0.381 \\
(0.270)\end{array}$ & $\begin{array}{c}-0.368 \\
(0.249)\end{array}$ & $\begin{array}{c}-0.344 \\
(0.244)\end{array}$ \\
\hline Han & & $\begin{array}{c}0.523 \\
(0.557)\end{array}$ & $\begin{array}{c}0.214 \\
(0.530)\end{array}$ & $\begin{array}{c}0.138 \\
(0.555)\end{array}$ & & $\begin{array}{c}0.688 \\
(0.629)\end{array}$ & $\begin{array}{c}0.105 \\
(0.585)\end{array}$ & $\begin{array}{l}0.0591 \\
(0.608)\end{array}$ \\
\hline Family income & & $\begin{array}{l}0.0283 \\
(0.226)\end{array}$ & $\begin{array}{c}0.00322 \\
(0.243)\end{array}$ & $\begin{array}{l}0.0365 \\
(0.207)\end{array}$ & & $\begin{array}{l}-0.0801 \\
(0.221)\end{array}$ & $\begin{array}{l}-0.128 \\
(0.261)\end{array}$ & $\begin{array}{l}-0.108 \\
(0.239)\end{array}$ \\
\hline
\end{tabular}

\footnotetext{
${ }^{38}$ Specifications including the double and triple interactions parallel to those inTable 3 have also been tested in variants of the TG regressions corresponding to Table 2, with Outgroup instead of Mixed in the interactions. These results are also available on request. The added interaction terms lack significant coefficients and impact on other coefficients of interest, except that the coefficient on Outgroup loses significance when the interaction between Outgroup and Han is added, which suggests that the difference between TG sending under Unknown and Outgroup conditions is mainly driven by Han subjects' behaviours. This could also be seen from Figure 2, which shows that with the condition changed from Unknown to Outgroup, Han sent 1 ECU more while Uyghur only sent $0.5 \mathrm{ECU}$ more on average.
} 


\begin{tabular}{|c|c|c|c|c|c|c|c|c|}
\hline $\begin{array}{l}\text { Lived outside of } \\
\text { Xinjiang } \\
>6 \text { Months }\end{array}$ & & $\begin{array}{c}1.067 \\
(0.981)\end{array}$ & $\begin{array}{c}1.236 \\
(0.981)\end{array}$ & $\begin{array}{c}1.291 \\
(0.876)\end{array}$ & & $\begin{array}{c}1.316 \\
(0.892)\end{array}$ & $\begin{array}{l}1.570^{*} \\
(0.857)\end{array}$ & $\begin{array}{l}1.603 * \\
(0.808)\end{array}$ \\
\hline $\begin{array}{l}\text { Han } \times \text { Lived outside } \\
\text { of Xinjiang } \\
>6 \text { Months }\end{array}$ & & $\begin{array}{l}-0.816 \\
(1.346)\end{array}$ & $\begin{array}{l}-0.959 \\
(1.367)\end{array}$ & $\begin{array}{l}-1.115 \\
(1.265)\end{array}$ & & $\begin{array}{l}-1.231 \\
(1.334)\end{array}$ & $\begin{array}{l}-1.445 \\
(1.311)\end{array}$ & $\begin{array}{l}-1.540 \\
(1.253)\end{array}$ \\
\hline Han $\times$ Mixed & & $\begin{array}{c}0.103 \\
(0.522)\end{array}$ & $\begin{array}{c}0.103 \\
(0.524)\end{array}$ & $\begin{array}{c}0.103 \\
(0.524)\end{array}$ & & $\begin{array}{l}-0.0277 \\
(0.581)\end{array}$ & $\begin{array}{l}-0.0277 \\
(0.584)\end{array}$ & $\begin{array}{l}-0.0277 \\
(0.585)\end{array}$ \\
\hline $\begin{array}{l}\text { Mixed } \times \text { Lived } \\
\text { outside of Xinjiang } \\
>6 \text { Months }\end{array}$ & & $\begin{array}{c}0.847 \\
(0.547)\end{array}$ & $\begin{array}{c}0.847 \\
(0.549)\end{array}$ & $\begin{array}{c}0.847 \\
(0.550)\end{array}$ & & $\begin{array}{c}0.591 \\
(0.531)\end{array}$ & $\begin{array}{c}0.591 \\
(0.533)\end{array}$ & $\begin{array}{c}0.591 \\
(0.534)\end{array}$ \\
\hline $\begin{array}{l}\text { Mixed } \times \text { Han } \times \text { Lived } \\
\text { outside of Xinjiang } \\
>6 \text { Months }\end{array}$ & & $\begin{array}{l}-1.025 \\
(0.759)\end{array}$ & $\begin{array}{l}-1.025 \\
(0.762)\end{array}$ & $\begin{array}{l}-1.025 \\
(0.762)\end{array}$ & & $\begin{array}{l}-0.601 \\
(0.820)\end{array}$ & $\begin{array}{l}-0.601 \\
(0.823)\end{array}$ & $\begin{array}{l}-0.601 \\
(0.825)\end{array}$ \\
\hline $\begin{array}{l}\text { Parent w/ } \\
\text { college degree }\end{array}$ & & $\begin{array}{l}-0.629 \\
(0.813)\end{array}$ & $\begin{array}{l}-0.485 \\
(0.818)\end{array}$ & $\begin{array}{l}-0.678 \\
(0.708)\end{array}$ & & $\begin{array}{l}-0.635 \\
(0.767)\end{array}$ & $\begin{array}{l}-0.340 \\
(0.765)\end{array}$ & $\begin{array}{l}-0.457 \\
(0.704)\end{array}$ \\
\hline Satisfaction & & & $\begin{array}{l}-0.0393 \\
(0.0885)\end{array}$ & $\begin{array}{l}-0.0290 \\
(0.0831)\end{array}$ & & & $\begin{array}{l}-0.0825 \\
(0.0994)\end{array}$ & $\begin{array}{l}-0.0763 \\
(0.0966)\end{array}$ \\
\hline WVS trust & & & $\begin{array}{c}0.596 \\
(0.451)\end{array}$ & $\begin{array}{c}0.866 \\
(0.495)\end{array}$ & & & $\begin{array}{l}1.086^{*} \\
(0.528)\end{array}$ & $\begin{array}{l}1.251 * * \\
(0.565)\end{array}$ \\
\hline $2^{\text {nd }}$ year & & & $\begin{array}{c}0.390 \\
(0.634)\end{array}$ & $\begin{array}{c}0.573 \\
(0.660)\end{array}$ & & & $\begin{array}{c}0.301 \\
(0.761)\end{array}$ & $\begin{array}{c}0.413 \\
(0.783)\end{array}$ \\
\hline Constant & $\begin{array}{c}2.983 * * * \\
(0.328)\end{array}$ & $\begin{array}{c}2.811 * * * \\
(0.802)\end{array}$ & $\begin{array}{c}2.935^{* *} \\
(1.135)\end{array}$ & $\begin{array}{l}2.119 * \\
(1.181)\end{array}$ & $\begin{array}{c}2.983 * * * \\
(0.328)\end{array}$ & $\begin{array}{c}3.058 * * * \\
(0.754)\end{array}$ & $\begin{array}{c}3.411 * * \\
(1.214)\end{array}$ & $\begin{array}{l}2.914 * * \\
(1.224)\end{array}$ \\
\hline Observations & 480 & 476 & 476 & 476 & 360 & 357 & 357 & 357 \\
\hline R-squared & 0.288 & 0.304 & 0.311 & 0.329 & 0.097 & 0.124 & 0.150 & 0.159 \\
\hline
\end{tabular}

Notes: OLS estimations clustering by session. Dependent variable is the amount (ECU) invested in PGG. Unknown dummy is the omitted category. Order dummy denotes the first 8 sessions where the four public goods games played were under Mixed, Unknown, Homogeneous, and Communication conditions respectively. Interaction number $=1,2,3,4$ denotes that the observation came from the $n t h$ public goods game played by the subject. Robust standard errors in parentheses.

$* * * \mathrm{p}<0.01, * * \mathrm{p}<0.05, * \mathrm{p}<0.1$
(1)-(4): Full sample
(5)-(8): Without communication

The coefficients of the interaction condition dummies in Table 3 confirm the findings of the non-parametric tests. The effects of the group ethnic composition in the three PGG interactions hold both when models are estimated on the sample that includes the Communication condition choices (models (1) - (4)) and when the latter observations are omitted (models (5) - (8)). In particular, we find positive significant coefficients for Homogenous and Mixed condition, indicating that subjects contributed significantly more in 
those conditions than in the default Unknown condition, with the coefficient always larger for Homogeneous than for Mixed ( $p<0.05$ for all models, nested F-tests), indicating that among these two conditions of play with known counterparts, that with a group of own ethnicity is associated with a higher contribution. In models (1) - (4), we also find the largest condition effect for Communication condition (compared with Homogeneous, $p<0.01$ for models (1) (4), nested F-tests), confirming that subjects contributed most following communication, and that going from a mixed group without to a mixed group with communication increased cooperation more than going from a mixed to a homogeneous group without communication.

\subsection{Correlations among sending, returning, and cooperating decisions}

So far, we have devoted little attention to the way behaviors correlate across decisions for given individuals, since the main concern of our paper is with differences in how members of the Uyghur and Han ethnic groups behave within their own group and with members of the other group. In this subsection, we investigate how subjects' behaviors in the TG and PGG correlate on the individual level. For example, do subjects who send more as $1^{\text {st }}$ movers also return more as $2^{\text {nd }}$ movers? Are $1^{\text {st }}$ mover sending or $2^{\text {nd }}$ mover returning in the TG or both significantly associated with contributing to the group account in the PGG? These are questions of considerable interest to the general study of trust and cooperation, but for reasons of space, we place the relevant correlation tables in Appendix C Table A6 - A8, and here mention only a few main findings.

First, it is indeed the case that those who are more trusting as $1^{\text {st }}$ movers are also significantly more trustworthy as $2^{\text {nd }}$ movers, overall; for example, sending as $1^{\text {st }}$ mover and returning as $2^{\text {nd }}$ mover have a correlation of .228 which is significant with $p=.0124$ for the full sample and at a similar level among Uyghur subjects taken alone, although insignificant among Han subjects alone. Second, both $1^{\text {st }}$ mover sending and $2^{\text {nd }}$ mover returning (as share of tripled amount) are significantly positively correlated with contributing in the PGG; for 
example, considering the Coethnic TG condition and the Homogeneous PGG condition, the correlation for $1^{\text {st }}$ mover sending is significant at the $1 \%$ level and that for $2^{\text {nd }}$ mover return share is significant at the 5\% level. These correlations are consistent with the ideas that (a) sending in the TG depends on the counterpart's predicted returning behavior which subjects forecast based on how they themselves play the role (see above and Kim et al., 2017), and (b) many subjects are conditional cooperators who contribute in the PGG if they believe others will do so, forming the belief in part based on own tendency towards reciprocity (which correlates with TG returning, beliefs about others' TG returning, and hence own TG sending).

Third, we note that while we found above many statistically significant differences in behavior towards own group versus other or mixed group members, there is nevertheless a great deal of consistency of given individuals' choices across the heterogeneous versus homogeneous conditions. Thus, $1^{\text {st }}$ mover TG sending, $2^{\text {nd }}$ mover TG returning (share), and PGG contribution are, for the full sample, highly correlated in Coethnic versus Outgroup and in Homogeneous versus Mixed conditions, with all three correlations being significant at the 0.0001 level. Thus, while behaviors do differ somewhat by group and condition, the inclinations of each individual usually affect his or her choices under those conditions in rather similar ways.

\subsection{A Han-Uyghur asymmetry: Cooperation vs. trust?}

In the previous subsection, we see that cooperation and trust correlate positively on the individual level. We now ask: is this true at the ethnic group level, as well? That is, does the more trusting ethnic group also tend to be more cooperative? From the discussion in Section 2 on the distinctively different historical and cultural backgrounds of Uyghur and Han, we suspect that this consistency between trust and cooperation may not hold on the group level. Specifically, we hypothesize that there may be a Han-Uyghur asymmetry, in the 
sense that while Uyghur subjects are more trusting than Han subjects in the TG, they are less cooperative in the PGG.

A glance of Figure 2 and Figure 5 seems to support this hypothesis. From Figure 2, we can see that in the TG, Uyghur participants on average sent more money than Han subjects in two of three conditions (Coethnic and Unknown), and the two ethnicities sent similar amounts on average to out-group members; while Figure 5 shows that in the PGG, Han participants tended to contribute more than Uyghur ones did in all four conditions. We now look at formal tests and regressions to see if these differences are statically significant.

To make things comparable between the observations from the TG and those from the PGG, we only consider the PGG conditions without communication, and we pair each remaining PGG condition with the most similar TG condition. Specifically, the "Coethic" condition in the TG corresponds to the "Homogeneous" condition in the PGG, while "Outgroup" corresponds to "Mixed", and "Unknown" corresponds to "Unknown". According to Mann-Whitney tests, the difference between amounts sent or contributed by Han versus Uyghur subjects is not statistically significant in all three conditions of either TG or PGG ( $p$ $=0.6777,0.8238,0.3274$ respectively in TG; $p=0.2804,0.4856,0.3017$ respectively in PGG). The behavioral pattern difference between Uyghur and Han in amount sent or contributed is also not significant when the three conditions are pooled together (average amount sent or contributed under the three conditions, $p=0.5311$ in TG and $p=0.2685$ in PGG).

When we go back to the regression results, we also find that the coefficient on the Han dummy is not significant in both TG and PGG, when all demographic covariates and interaction terms are controlled. To take a closer look at the effects of ethnicities in the TG and PGG, we run separate regressions for each condition. In the TG, we find a significant effect of Han in the Unknown condition, but not in the other two conditions (see Appendix C 
Table A4). Specifically, when facing unknown players, on average Uyghurs send 1.209 more ECU than Hans do $(p<0.05)$, with the same controls as in Table 2 column (4). In the PGG, the coefficient on Han is never significant in any conditions with the Han $\times$ Lived outside of Xinjiang > 6 Months interaction term and all demographic covariates controlled (see Appendix C Table A5).

Given the above insignificant results, we turn to a weaker criterion of the hypothesized Han-Uyghur asymmetry, differences between Han and Uyghur subjects in the propensity to cooperate in a group versus to trust dyadically. To measure this propensity for

each subject, we use the ratio of average amount of money he or she sent in the PGG (without communication) to the average amount sent as $1^{\text {st }}$ mover in the TG, which means that we are focusing on the inclination to cooperate relative to the tendency to trust. The Mann-Whitney test shows that the "cooperation-to-trust ratio" does significantly differ between Uyghur and Han subjects: Uyghur subjects' ratio of average PGG sending relative to average $1^{\text {st }}$ mover trust is significantly lower than that of Han subjects, with $p=0.0187$. We also run a MannWhitney test for the cooperation-to-trust ratio of each pair of corresponding conditions in the TG and PGG (e.g., amount contributed within a homogeneous ethnicity group in the PGG over amount sent to coethnic in the TG), and see that Uyghur subjects' cooperation-to-trust ratios are significantly lower than Han subjects' ratios under "Homogeneous/Coethnic" and "Mixed/Outgroup" ( $p=0.0975,0.0537)$ while there is no significant difference when facing randomly assigned unidentifiable counterparts $(p=0.6505)$.

\section{Ethnic favoritism, identifiability and communication: discussion}

In this section, we discuss the impact of identifiability and communication on interethnic trust and cooperation, as found in Section 4. We argue that the comparisons made 
possible by our Unknown and Communication conditions underscore the fact that the magnitude of the outgroup vs. ingroup effect is of relatively modest size, in our data.

\subsection{Known versus randomly chosen counterparts}

Recall that with respect to differences between conditions (Coethnic, Mixed, Unknown), we found the same ordering for members of both ethnic groups: for both groups, both trusting and cooperating were greater in pairs or groups of same ethnicity than in pairs or groups of mixed ethnicity, but trusting and cooperating were smallest in groups of unknown composition. The fact that members of both groups were more trusting towards and willing to cooperate with those of the same ethnicity is not entirely surprising, even though not all results in the literature display this pattern. However, the finding that trust and cooperation are lower when the counterpart's (counterparts') ethnicity is unknown appears inconsistent with the homogeneous vs. heterogeneous ordering if one thinks only of ethnicity and does so only probabilistically, since each counterpart has a nearly equal chance (in our setting) of being a coethnic or of the other ethnicity, and outcomes for the unknown ethnicity cases might therefore (by an "expected identity" type reasoning) be expected to fall in between those for homogeneous and for mixed ethnicity interactions. The explanation of why this reasoning does not predict behaviors, we think, lies in the fact that both $1^{\text {st }}$ and $2^{\text {nd }}$ movers in the homogeneous and mixed ethnicity conditions could identify their counterparts by sight, as specific individuals, whereas in the unknown counterpart condition each interaction partner could turn out to be any of seven other participants in the session, and the counterpart(s)' actual identity would never be revealed. A plausible interpretation, therefore, is that partner concreteness (a dimension of social distance, viewed broadly) led to more "sociable" behaviors in both homogeneous and mixed pairs relative to the unknown partner 
condition. Largely the same seems to apply also to returning behavior or trustworthiness. ${ }^{39} \mathrm{In}$ Hoffman et al. (1996), as social distance/isolation increases towards a "double blind" treatment resembling our "purely unknown" condition, there is a further shift toward less cooperation between partners, which means that subjects behave in a more strictly selfinterested way.

\subsection{Impact of communication}

In Subsection 4.3, we see that despite the fact that contributions are lower in mixed than in ethnically homogeneous groups, initially, contributions in the interactions in mixed groups permitted to communicate before playing are highest, among all conditions.

Substantially and significantly higher contributions with communication are somewhat unsurprising in view of the similar results for voluntary contribution experiments with faceto-face communication cited above (see Subsection 3.3). To be sure, traditional game theory predicts zero contribution in the PGG regardless of what words are exchanged, and even if there might be social consequences of going back on the word one has given to fellow students, that should be of no account in our set-up, since participants return to their individual seats, mark their decisions out of others' views, and learn of the overall outcome only. But many experiments find positive effects of such communication on cooperation and trust (Sally, 1995, Ben-Ner et al., 2011, Ellingsen et al., 2009), possibly attributable to some combination of conditionally cooperative preferences (Fischbacher and Gächter, 2010) bolstered by the impact of the exchanged declarations of intention to contribute on beliefs of

\footnotetext{
39 Subjects eventually learned only their total earnings from all games and thus could not impute the behavior of any specific partner. This was explained to them in the instructions, so ideally they should not have been concerned with how a specific counterpart's reaction would affect their relationship in the future. We cannot strictly rule out, though, that some participants, for whom the entire procedure was novel, attached a non-zero probability to an identifiable counterpart discovering how they had behaved, while attaching lower or zero probability to the counterpart in the unknown identity condition obtaining such information. However, we conjecture that the conflict avoidance factor as such played at most a minor role, and that the effect of identifiability was operative mainly for psychological reasons associated with the concreteness and specificity of interaction partners.
} 
fellow participants, aversion to lying or to disappointing others (Charness and Dufwenberg 2006, Vanberg 2008, Ellingsen et al. 2009), and the possibility that participants having a better understanding of the social dilemma successfully convince others of the mutual benefit of cooperation (Bochet et al. 2006).

What is novel about our finding on communication is its inter-ethnic context. To our knowledge, the result that communication trumps homogeneous ethnic group sorting as a spur to cooperation has not been reported elsewhere. Also, our experiment entails a somewhat stiffer test of communication's impact than in many past tests of communication's impact in that our subjects get no feedback regarding other group members' behaviors in any individual interaction, which effectively increases anonymity at the decision-making stage. Although quite possibly cooperation would be higher still had we been able to observe an interaction with communication in ethnically homogeneous groups, it is nonetheless interesting and argues against the most pessimistic views regarding the potential for cooperation between members of the Uyghur and Han ethnic groups in urban Xinjiang that, when comparing the comparative statics of a move from PGG play in heterogeneous groups without communication to corresponding play in (i) homogenous groups without communication, and (ii) in heterogeneous groups with communication, it is the second transition which yields substantially more cooperation..$^{40}$

\subsection{Magnitude of the outgroup vs. ingroup effect}

A major finding of our paper is that we find Uyghur and Han subjects conform to the common expectation that trust and cooperation tend to be greater between members of a given group than when members of different groups are involved. However, it seems important not to exaggerate the degree of discomfort that our subjects display when dealing

\footnotetext{
${ }^{40}$ Regarding the concern that the communication interaction is always last and might thus reflect an order effect, see footnote 24 above. Note also that the Interaction number variable was found to be insignificant in all regressions of Table 3.
} 
with members of the outgroup or playing in a mixed group. The facts that sending, returning, and contributing tend to be greater even with outgroup and mixed pairings than with anonymous others who could well be of one's own ethnicity, and that adding communication to a mixed group does more for cooperation in the PGG than does switching to homogenous membership, both speak to the relative modesty of the difference between coethnic and mixed interactions, since if aversion to interacting with outgroup members were strong enough, neither finding need hold.

The most plausible explanation of why subjects are more trusting and trustworthy with identifiable than with strictly anonymous and unidentifiable others is that this is a social distance effect, as argued in sub-section 5.1. If the sense of distrust, lack of reciprocal obligation, and disinclination to cooperate between our Han and Uyghur participants were more pronounced, then identifiability per se might not achieve so substantial a social distance effect as we observe.

A similar point can be made about communication. Subjects in other experiments have been observed to cooperate significantly more after having the opportunity to communicate, but this depends on their ability to build trust with respect to one another's words and intentions. Were Han and Uyghur participants sufficiently distant and untrusting, each participant would have only one coethnic member in their mixed communication group whose word they could put trust in, plus two outgroup members whose word they might trust little if at all. Thus, an outcome in which cooperation were greater in homogeneous groups without communication than in heterogeneous ones with communication could not be ruled out.

The fact that neither of these counterfactual possibilities in fact occurs rests in part on the relatively small magnitude of the outgroup vs. ingroup effect that we observe in our data. 
We think that the modest magnitude of the effect deserves nearly as much attention as the fact that the effect is observed and is statistically significant, in the first place.

\section{Conclusion}

We use canonical incentivized decision experiments to study trust and cooperation both within and between members of the two main ethnic groups of China's westernmost province-level region, an area with centuries of history as a borderland between largely Muslim central Asia and East Asia's perennial core state, China. To be sure, students at an ethnically well-balanced three-year college in Xinjiang's capital city are not necessarily representative of the region's population as a whole. They are, nonetheless, drawn from a fairly wide variety of backgrounds, the school is not a particularly elite one, and the research was conducted on short notice without administrative interventions. In view of the difficulty of conducting social scientific research on inter-ethnic relations in the sensitive environment that is Xinjiang today, we believe our study provides a useful window into how members of Uyghur and Han populations perceive each other in at least some of their day to day interactions.

We use a novel method to induce both ethnically homogeneous and ethnically mixed play of each game, identifiable as such by subjects, yet never overtly referenced in any way in the experimental instructions or procedures. We find great similarity in how both groups play each game, each being somewhat more trusting and cooperative towards members of their own group than towards an outgroup member or in an ethnically mixed group. There is little indication of the type of asymmetry that has been observed in some cases where members of one group are trusted more than the other by those of both ethnicities, although we found qualitative similarity between the Uyghur-Han interactions in our paper and those between Palestinians and Israelis in Hennig-Schmidt et al. (2007) in one respect. 
Our results are arguably compatible with both theories of the impact of the state on social norms (Weber, 1976) and with Talhelm et al.'s (2014) “rice theory." Compared to Uyghurs, people of Han ethnicity have lived under the rule of strong centralized authorities for a long time, which might foster a culture of group cooperation under common rules. In addition, centuries of intensive farming may also have infused in many Han people a culture of collective action and interdependence. However, individual Han people are not more trusting of other individuals than Uyghur, who may have cultivated stronger norms about interpersonal obligations in comparatively small communities at scattered oases. Although Han subjects in our research cooperate better and Uyghur subjects trust others more, both these differences and the degree of discrimination against or distrust of outgroup versus ingroup is relatively modest, as gauged by the fact that (a) both trust and cooperation only fall by about $15 \%$ when comparing homogeneous versus heterogeneous play, (b) both trust and cooperation are higher with identifiable partners or group members belonging to the other group than with completely unknown (unidentifiable) partners or group members, (c) the availability of communication is more potent than is ethnic homogeneity for engendering cooperation (in the public goods game), and (d) ethnicity-specific differences in cooperation and trust are statistically significant only in ratio, and not when each action is studied separately. It is indeed possible that the ethnically mixed school that is the setting for our experiment engenders better relations between the two ethnic groups than exists between them in other settings. But if so, those hoping to improve trust and cooperation in Xinjiang might do well to explore ways of encouraging more such inter-ethnic engagement on a plane of relative equality and mutual respect. 


\section{References}

Alesina, Alberto, Reza Baqir, and William Easterly (1999). Public goods and ethnic divisions. Quarterly Journal of Economics 114(4): 1243-1284.

Bellemare, Charles and Sabine Kroeger (2007). On representative social capital. European Economic Review. 51(1), pp. 183-202

Ben-Ner, Avner, Louis Putterman and Ting Ren (2011). Lavish Returns on Cheap Talk: Two-Way Communication in Trust Games. Journal of Socio-economics 40: 1 - 13.

Berg, Joyce, John Dickhaut, and Kevin McCabe (1995). Trust, Reciprocity, and Social History. Games and Economic Behavior 10 (1): 122-42.

Bochet, Olivier, Talbot Page and Louis Putterman (2006). Communication and Punishment in Voluntary Contribution Experiments. Journal of Economic Behavior and Organization 60: 11 - 26.

Bovingdon, Gardner (2010). The Uyghurs: Strangers in Their Own Land. New York: Columbia University Press.

Brandts, Jordi and Gary Charness (2011). The strategy versus the direct-response method: a first survey of experimental comparisons. Experimental Economics, 14:375-398.

Brosig, Jeannette, Axel Ockenfels and Joaquim Weimann (2003). The Effect of Communication Media on Cooperation. German Economic Review 4: 217 - 242.

Charness, Gary and Martin Dufwenberg (2006). Promises and Partnerships. Econometrica. 74 (6): $1579-1601$.

Chen, Josie, Andrew Foster and Louis Putterman (2017). Identity, Trust and Altruism: An Experiment on Online One-to-One Microfinance Lending. unpublished paper, Brown University.

Distelhorst, Greg, and Yue Hou (2014). Ingroup Bias in Official Behavior: A National Field Experiment in China. Quarterly Journal of Political Science. 9 (2): 203-30. 
Easterly, William and Ross Levine (1997). Africa's Growth Tragedy: Policies and Ethnic Divisions. The Quarterly Journal of Economics, 112 (4): 1203-1250.

Ellingsen, Tore, Magnus Johannesson, Jannie Lilja and Henrik Zetterqvist (2009). Trust and Truth. Economic Journal 119 (534): 252 - 76.

Eckel, Catherine and Rick Wilson (2011). Trust and Social Exchange, pp. 243 - 257 in James Druckman, Donald Green, James Kuklinski and Arthur Lupia, eds., Handbook of Experimental Political Science. New York: Cambridge Uninversity Press.

Fehr, Ernst (2009). On the Economics and Biology of Trust. Journal of the European Economic Association 7 (2-3): 235 - 266.

Fehr E, Fischbacher U, Rosenbladt BV, Schupp J, Wagner G. (2003). A nation-wide laboratory: examining trust and trustworthiness by integrating behavioral experiments into representative surveys. Schmollers Jahrb. 122:519-42

Fershtman, Chaim and Uri Gneezy (2001). Discrimination in a Segmented Society: An Experimental Approach. Quarterly Journal of Economics 116 (1): 351 - 377.

Fischbacher, Urs and Simon Gächter (2010). Social Preferences, Beliefs, and the Dynamics of Free Riding in Public Goods Experiments. American Economic Review 100: 541 556.

Fischbacher, Urs, Simon Gächter, and Fehr, E. (2001). Are people conditionally cooperative? Evidence from a public goods experiment. Economics letters, 71(3), 397-404.

Fu, Tingting, Kenju Kamei, Louis Putterman and Yunan Ji, (2017). Punishment Can Support Cooperation even When Punishable. Economics Letters.154: 84 - 87.

Fukuyama, Frances (2011). The Origins of Political Order: From Prehuman Times to the French Revolution. New York: Farrar, Straus and Giroux. 
Gächter, Simon and Benedikt Herrmann (2008). Reciprocity, Culture and Human Cooperation: Previous Insights and a New Cross-Cultural Experiment. Philosophical Transactions of the Royal Society B, doi: 10.1098/rstb.2008.0275.

Glaeser, Edward, David Laibson, Jose Scheinkman, and Christine Soutter (2000). Measuring trust. Quarterly Journal of Economics.115(3): 811-846.

Gries, Peter, Matthew A. Sanders, David R. Stroup, and Huajian Cai (2015). Hollywood in China: How American popular culture shapes Chinese views of the "beautiful imperialist" - an experimental analysis. The China Quarterly, (224): 1070-1082.

Guan, Mei, and Donald Green (2006). Noncoercive Mobilization in State-Controlled Elections: An Experimental Study in Beijing. Comparative Political Studies. 39 (10): 1175-93.

Güth, Werner, Steffen Huck, Wieland Müller (2001). The Relevance of Equal Splits in Ultimatum Games. Games and Economic Behavior. 37(1): 161-169

Habyarimana, James., MaCartan Humphreys, Daniel Posner, and Jeremy Weinstein (2007). Why Does Ethnic Diversity Undermine Public Goods Provision? American Political Science Review. 101(4 ): 709-25

Hennig-Schmidt, Heike, Reinhard Selten, Gari Walkowitz, Eyal Winter, and Ihab Dakkak (2007). Actions and Beliefs in a Trilateral Trust Game Involving Germans, Israelis and Palestinians. Paper presented at Experimental Science Association (ESA) Conference, Rome, Italy. http://static.luiss.it/esa2007/programme/papers/221.pdf

Herrmann, B., S. Gachter, and C. Thoni (2008). Antisocial Punishment across Societies. Science. 319(5868): 1362-1367.

Hoffman, Elizabeth, Kevin McCabe, and Vernon Smith (1996). Social Distance and OtherRegarding Behavior in Dictator Games. American Economic Review. 86(3):653-660. 
Howell, Anthony and Fan, C. Cindy. (2011). Migration and Inequality in Xinjiang: A Survey of Han and Uyghur Migrants in Urumqi. Eurasian Geography and Economics, 52, No. 1, $119-139$.

Isaac, Mark and James Walker (1988). Communication and Free-Riding Behavior: The Voluntary Contributions Mechanism. Economic Inquiry 26: 585 - 608.

Johnson, Noel and Alexandra Mislin (2011). Trust games: a meta-analysis. Journal of Economic Psychology 32 (5): 865 - 889.

Khwaja, Asim (2001). Can Good Projects Succeed in Bad Communities? Collective Action in the Himalaya. Unpublished paper, Harvard University, http://siteresources.worldbank.org/DEC/Resources/84797-1251813753820/6415739$\underline{1251814028691 / \text { khwaja.pdf }}$

Kim, Jeongbin, Louis Putterman and Xinyi Zhang (2017). Trust, Beliefs and Cooperation: An Experiment. mimeo, Brown University.

Lazzarini, Sergio, Regina Madalozzo, Rinaldo Artes, and José de Oliveira Siqueira (2003). Measuring trust: an experiment in Brazil, Working Paper, WPE 01-2004, IBMEC Business School. https://core.ac.uk/download/pdf/6228649.pdf

Ledyard, John (1995). Public Goods: A Survey of Experimental research. In John Kagel and Alvin Roth, eds., Handbook of Experimental Economics, pp. 111 - 94. Princeton: Princeton University Press.

Lowes, Sara, Nathan Nunn, James Robinson and Jonathan Weigel (2017). The Evolution of Culture and Institutions: Evidence from the Kuba Kingdom. Econometrica. 85(4): 10651091.

Lü, Xiaobo, Kenneth Scheve, and Matthew J. Slaughter (2012). Inequity Aversion and the International Distribution of Trade Protection. American Journal of Political Science, 56 (3): 638-54. 
Lü, Xiaobo (2015). China: Ethical Challenges in Comparative Politics Experiments. In Ethics and Experiments: Problems and Solutions for Social Scientists and Policy Professionals, ed. Scott Desposato. London: Routledge.

Markussen, Thomas, Louis Putterman and Liangjun Wang (2017). Governing Collective Action in the Face of Observational Error. Brown University Department of Economics Working Paper no. 2017-2.

Miguel, Edward and Mary Kay Gugerty (2005). Ethnic diversity, social sanctions, and public goods in Kenya. Journal of Public Economics, 89 (11-12): 2325-2368.

Millward, James (2007). Eurasian crossroads: a history of Xinjiang. New York: Columbia University Press.

Montalvo, José, G., and Marta Reynal-Querol (2005). Ethnic Polarization, Potential Conflict, and Civil Wars. American Economic Review, 95(3): 796-816.

Naef, Michael and Jürgen Schupp (2009). Measuring Trust: Experiments and Surveys in Contrast and Combination. IZA Discussion Paper No. 4087.

Roth, Alvin (1995). Bargaining Experiments. In Handbook of Experimental Economics, ed. by John Kagel and Alvin E. Roth, 253-348. Princeton University Press.

Rudelson, Justin (1997). Oasis identities: Uyghur nationalism along China's Silk Road. New York: Columbia University Press.

Sally, David (1995). Conversation and cooperation in social dilemmas: A meta-analysis of experiments from 1958 to 1992. Rationality and Society 7: 58 - 92.

Sapienza, Paola, Anna Toldra - Simats, and Luigi Zingales (2013). Understanding Trust. The Economic Journal. 123(573): 1313-1332.

Starr, Frederick (2004). ed. Xinjiang: China's Muslim borderland. Armonk, N.Y.: M.E. Sharpe Inc. 
Talhelm, T., X. Zhang, S. Oishi, C. Shimin, D. Duan, X. Lan and S. Kitayama (2014). Largescale psychological differences within China explained by rice versus wheat agriculture. Science. 344, 603-608.

Weber, Eugene (1976), Peasants into Frenchmen: The Modernization of Rural France, 1870 - 1914. Stanford: Stanford University Press.

Wong, Stan Hok-Wui and Takeuchi, Hiroki (2013). Economic Assistance, Central-Local Relations, and Ethnic Regions in China's Authoritarian Regime. Japanese Journal of Political Science 14 (1) 97-125.

Zelmer, Jennifer (2003). Linear Public Goods Experiments: A Meta-Analysis. Experimental Economics 6: $299-310$.

Zhang, Shen, Miao Xu, Xueting Li, Huizhen Fang, Shengmin Yang, and Jia Liu (2013). Implicit Trust between the Uyghur and the Han in Xinjiang, China. PLoS One. 8(8): e71829.

Zhu, Yuchao and Dongyan Blachford (2012). Economic Expansion, Marketization, and their Social Impact on China's Ethnic Minorities in Xinjiang and Tibet. Asian Survey 52(4):714-733 